\title{
Communication studies about sex: Implications for relationships, health, culture, and identity. A review
}

\author{
Jimmie Manning
}

Nota: Este artículo se puede leer en español en:

http://www.profesionaldelainformacion.com/contenidos/2021/ene/manning_espanol.pdf

How to cite this article:

Manning, Jimmie (2021). "Communication studies about sex: Implications for relationships, health, culture, and identity. A review". Profesional de la información, v. 30, n. 1, e300114.

https://doi.org/10.3145/epi.2021.ene.14

Invited manuscript received on February, $2^{\text {nd }} 2020$

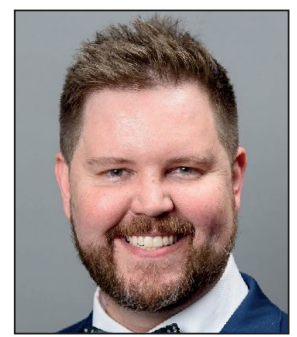

Jimmie Manning

https://orcid.org/0000-0002-3572-8005

University of Nevada

School of Social Research \& Justice Studies

Communication Studies - Mail Stop 0229

1664 N. Virginia Ave.

Reno, NV 89577 USA

jimmiem@unr.edu

\begin{abstract}
This article features a review of communication scholarship about sex from the past two decades (2000-2020). A typographic analysis of relevant research reveals 11 primary topic areas related to how interpersonal sexual communication is commonly researched in communication studies. Six of these topic areas are relationship-oriented in nature: flirting and initiation; pleasure and desire; sexual expectations; relational and sexual satisfaction; communication after sex; and negative aspects of sex and sexuality. Three of the topics are health-oriented in nature: sex education, especially in consideration of how parent-child talk happens in families; negotiation of safe sex practices; and sexual dysfunction. Finally, two of the topics are cultural in nature: social factors and influences; and media influences and representations. Scholarship is also reviewed in terms of theoretical commitments, with most research following sociopsychological or critical traditions but with a noteworthy number also embracing sociocultural or biological paradigms. Based on these observations, five directions are offered for future research: supporting programs of interpersonal sex research; advancing and/or creating methods related to communication sex research; eliminating heteronormativity; considering the practical aspects of sex research; and, perhaps most importantly, theorizing sex as communication.
\end{abstract}

\section{Keywords}

Constitutive communication theory; Discourse; Family communication; Health communication; Heteronormativity; Interpersonal communication; Media studies; Methodology; Online sexuality; Practical theory; Queer theory; Sex as communication; Sex positivity; Sexuality; Typology development.

\section{Introduction}

Communication studies, as a field, appears to have a sex problem. Studies abound when it comes to sexual identities, mass-mediated/popular representations of sex and sexuality, and topics such as pornography; but when it comes to research about actually having sex as well as the talk that leads there, the scholarship is largely medical-oriented or largely based on cultural discourses (Manning, 2014b). That is, few people actually seem to be examining interpersonal aspects of sexuality and especially not the talk that might happen during sexual acts. To wit, in The handbook of sexuality in close relationships (Harvey; Wenzel; Sprecher, 2004), a cross-disciplinary resource exploring sexuality in relationships, communication topics can only be found on 20 of the 686 pages of the handbook. Although that number is quite small, it is still better than what is revealed when considering the subfield of interpersonal

Few people actually seem to be examining interpersonal aspects of sexuality and especially not the talk that might happen during sexual acts 
communication studies. Sex, sexuality, sexual identity, and any other ostensibly sex-oriented topic are missing from The Sage Handbook of Interpersonal Communication (Knapp; Daly, 2011).

As these facts suggest, sex is being omitted, underrepresented, or ignored in close relationship and interpersonal outlets. This ambivalence is in notable contrast to other areas of the communication discipline. As a number of scholars have recently noted (e.g., Comella; Sender, 2013; Noland, 2010), the field of communication is seeing an unparalleled uptick in the development of sex scholarship. Unfortunately, as scholars have also noted (e.g., Adams, 2011; Manning, 2013) and as lack of representation in disciplinary handbooks suggests, the area of interpersonal communication studies has been slow to join this movement. Given that interpersonal interaction and processes are central to many communication transactions, this particular lack of momentum regarding sexual communication research extends beyond one area of the discipline and has potential implications for other areas of communication studies. In this essay I point to four particular areas of knowledge that could benefit from more-substantial understandings of interpersonal communication about sex: relationships, health, culture, and identity.

To begin this exploration, I review recent research regarding what I call interpersonal sexuality and how that impacts sexual communication. Combined, these terms point to the topical area of interpersonal sexual communication, one that, based on the evidence presented in this article, is largely ignored. After unpacking these key terms and explaining my approach to a review of relevant literature from 2000-2020, I go in-depth into the literature to indicate what topical areas have been covered, what theoretical traditions have been embraced, and how those who study interpersonal sexual communication might move forward with their work.

In exploring past research and then bringing it together to consider larger understandings of where sexual communication research can move next, I take a constitutive interpersonal approach (Manning, 2014c). As scholars have noted, many times interpersonal communication studies are dominated by or limited to sociopsychological or cybernetic theoretical approaches. The implications of this limited theoretical range have an impact on method, meaning post-positive statistical studies often dominate interpersonal communication scholarship (Braithwaite; Schrodt; Carr, 2015). In response, I cast a wider net with this exploration to identify sexual interpersonal communication scholarship that might not always be viewed as traditional or even as being included in interpersonal communication studies.

I point to four particular areas of knowledge that could benefit from more-substantial understandings of interpersonal communication about sex: relationships, health, culture, and identity

\subsection{Methods for the review}

To begin this review, I searched for relevant and recent literature using the Communication and Mass Media Complete database. I entered several search strings in order to try and gain a large number of articles related to interpersonal sexual communication since the turn of the millennium (2000-2020). Terms used for the search include various combinations of either interpersonal, interaction, relational, or relationship combined with one or more of the following terms: sex, sexual, sexuality, sexual identity, sexual communication, sex talk, queer, sexual orientation, intercourse, intimacy, and/or sexual interaction. Because the word sex has different meanings in relation to research, many articles were returned in searches that had no ostensible relationship to sex (the act) but instead used sex or gender as a variable or demographic descriptor. Those articles were discarded. Following this purge, 349 articles remained. I also found reviews for seven books in these searches, and because two of them were specifically about sex and communication they were added to the reading list.

The resulting 351 resources were closely examined to determine if they were about interpersonal sexuality. To that end, and in line with my review goals, they had to meet three standards to remain.

- First, the work had to deal specifically with communication between two or more people that was about sex. This rule eliminated many studies that examined media effects (e.g., the cognitive or affective impacts a television program or movie had on viewers) as well as studies that made connections between non-communicative psychosocial characteristics and number of sexual partners (e.g., a count study that examines the number of people someone has had sexual intercourse with over a particular time period).

- Second, sex, for the purposes of this project, needed to be related to actual physical acts or potential actual physical acts. This resulted in the elimination of many studies that were more about sexual orientation or identity.

- Finally, the study had to contribute something novel about sex and communication. In other words, it was not enough for sex to be merely present in the study (e.g., age of first sex used to characterize a finding about relational communication); it also needed to be observed and theorized about, even if only in subtle or tangential ways. After applying these rules, 137 articles or books remained.

I then indexed the authors for each of these remaining works and searched for them using Google Scholar, Academia. edu, and ResearchGate. This process allowed me to see if other research by these authors was available that did not come up in the database search. Again, I applied the three standards of inclusion, and this resulted in 26 additional books or articles being added to the review. At this point, I considered the collection of scholarship a good corpus of 
research to consider current trends in the field. These 173 sources were then analyzed using typology development (also known as typographic analysis; see Manning; Kunkel, 2014b) to divide the work based on topic areas. This analysis quickly made it apparent that, in terms of communication research about interpersonal sex, works tended to either foreground a relationships-oriented perspective (both in the casual or more enduring relational sense; $n=61$ ) or a health-oriented perspective $(n=76)$. A smaller number of these articles focused on some aspect of culture, including some traditional media studies $(n=36)$.

Notably, this approach was limited in that all articles and books collected for the data set were written in English; and, because "communication studies" as a discipline is more of a United States enterprise, the literature was also skewed toward U.S.-centric perspectives -although, notably, many studies did not indicate the origin of the participants. To help indicate geographical diversity, when studies indicated the nation of origin for participants that information is included in this review.

\subsection{Reviewing sex and relationships in communication studies}

In conducting the typographic analysis and reviewing the literature, it was apparent that some topical areas about relationships and communication were quite robust, whereas other topics were limited to one or two articles. As such, some topical areas were able to be divided into subtopics. Following Stamp's (1999) rationale for examining interpersonal literature, I considered how I could "weave these threads together into a coherent tapestry" (p. 531) that considered the specifics of each study while pointing to topical patterns. Doing so allows sex researchers both to see what interpersonal sexual communication studies have to offer and where future research might be needed. Further, given that the articles about a given topic often reached across methodological and theoretical paradigms, I sought to treat these articles not only as information that could be combined and assessed, but also as a unit of discourse that constitutes part of a larger discourse that is the field of sexuality studies in communication. With that justification, I constructed a first guiding question for this review: What are the salient topics of interest in recent studies of interpersonal communication about relationships and sex?

A caveat here: I present all of these themes and sub-themes as part of this review, both as a way of "showing my work" but also so that those who are interested in a particular topic or concept can discover literature of interest. This portion of the review is less about theorizing and conceptualizing than it is presenting a record of the existing work as it currently stands. That, in turn, provides a sense of what the field looks like in terms of topical traction as well as the methods or approaches scholars are using to do studies of sexual interpersonal communication. To that end, it could be helpful to think of sections 2-4 of this paper as an annotated bibliography, of sorts, where readers can especially focus on the topics or concepts that are more relevant to their own work or that rouse personal interest.

Moving to a second guiding question, it was also apparent from reviewing the literature that interpersonal communication was being studied across many different communication traditions. As Craig (1999) notes, communication as a field often finds its greatest strengths when its various traditions can be explored together or side-by-side to create a constitutive view of a topic or phenomenon. In other words, considering similarities and differences across theoretical lenses provides a fuller, more nuanced sense of the topics being studied and theorized. Further, Manning (2014c) argues that researchers across different traditions in interpersonal communication studies need to acquaint themselves with each other's work to both inspire the work they do in their own paradigms as well as to expand the scope, generalizability, transferability, and/or practicality of interpersonal communication theory.

To help ensure that this review does not fall into the same silos that plague many other forms of interpersonal communication and communication studies in general, a second guiding question was developed: What is the metadiscursive theoretical vocabulary for studying

\section{Interpersonal communication is being studied across many different communi- cation traditions}

sex and relationships in interpersonal communication studies? In answering this question, the fifth section of this article not only provides a good sense of the theoretical domains driving sexual interpersonal communication studies; but it provides a good metatheoretical vocabulary for discussing interpersonal sexuality research and its findings.

Finally, after considering the topical and theoretical and terrains that researchers have covered, it made sense to consider what turns or directions might be beneficial to future studies of interpersonal sexuality. That led to a third and final guiding question for this review: What future directions might be fruitful for expanding, refining, and utilizing studies of interpersonal sexuality related to relationships? To that end, the sixth and final section of this review offers a five-part agenda for sexual interpersonal communication research inspired by an evaluation of the content of the research articles and books used for this project. 


\section{A review of relationship-oriented research about sexual communication}

In response to the first guiding question for this review, 6 topic areas primarily related to relationships were identified:

- flirting and initiation,

- pleasure and desire,

- sexual expectations,

- relational and sexual satisfaction,

- communication after sex, and

- negative relational topics.

Despite these types of studies being more prevalent in general interpersonal communication research, only 61 of 173 total studies about interpersonal sexual communication were sorted into this domain.

\subsection{Flirting and sexual initiation}

The most dominant topic area in terms of relational sexual communication is flirting and sexual initiation. This research was divided into two subtopical areas, one representing face-to-face contexts and another representing online interaction.

\section{a) Flirting and initiation in face-to-face contexts}

Studies exploring flirting dominate the interpersonal sexual communication literature. Indeed, one of the few programmatic research programs discovered in the entire review of the literature review focused on the relationships between flirting and sexual interest. Specifically, in one study, Henningsen (2004) found that women tended to see flirting as more related to relational initiation or having fun, whereas men were more likely to attribute it to being sexual. A follow-up study (Henningsen; Henningsen; Valde, 2006) again revealed that men and women interpret the same flirting interactions differently, with men seeing more cues as indicating sexual interest than did women. That study also indicates that men perceived the pursuit of sexual interaction as more appropriate behavior than did women. A third study (Henningsen; Braz; Davies, 2008) de-

The most dominant topic area in terms of relational sexual communication is flirting and sexual initiation monstrates that office workers are less likely to see flirting as motivated by relational or sexual intentions in comparison to college students. This particular study calls into question how much faith can be placed in many of the interpersonal sexuality studies reviewed for this project, as a large number of the articles reviewed for this project exclusively used college students for their participants.

A fourth study from Henningsen's line of flirting research (Henningsen et al., 2009) explores verbal and nonverbal cues. Findings indicate that when verbal cues are used, both men and women are less likely to see a difference in sexual interest; whereas with nonverbal cues, men see more sexual interest in the communication than women. Finally, a meta-analysis of both flirting perceptions as well as perceptions of seductiveness and what the researchers label as "promiscuousness" was conducted to explore relationships between the three (La-France; Henningsen; Oates; Shaw, 2009). Results indicate positive and statistically significant weighted correlations between flirtatiousness, seductiveness, and promiscuousness both in terms of the sex of the person being observed as well as the mode of that observation (e.g., videotaped segment, photograph, etc.). Collectively, Henningsen's line of work, all conducted within the U.S., provides an indication of differences in how flirting cues are perceived by men and women. Aside from Henningsen's work, other studies have examined flirting using relational framing theory (Hall, 2015) and error management theory (Hall; Xing; Brooks, 2015), among others.

Beyond flirting, other studies more directly examine how sexual activity is initiated or the results of initiating such activity. For example, Browning, Hatfield, Kessler, and Levine (2000) examine four motives for initiating sex -love, pleasure, conformity, and recognition- and consider them in interaction with gender. They found that gender was the most important predictor of initiating usual sexual behavior, although love was the best predictor of actually engaging in sex regularly. Also related to gender, Parker and Ivanov (2013) found that younger women are especially likely to report that men are the initiators for sexual interaction. Turning to a study that features implications about how some gay, lesbian, and bisexual (GLB) people initiate sex, Manning (2015a), drawing from a multinational participant pool, found that some people come out, or reveal their sexual identity for the first time, by trying to initiate sexual activity with a person they also believe to be GLB. Still, the majority of research about flirting and sexual initiation features participants who are assumed to be heterosexual. Communication sex researchers should consider examining non-heterosexual participants as they develop future studies.

\section{b) Online sexual partners}

Other initiation studies focus on online sexual partners. For example, Peter and Valkenburg (2007) sought to understand what leads people to look for sex online. In their survey of 729 Dutch adults, they found support for the recreation hypothesis, or the idea that sensation seekers and sexually-permissive people will pursue people online via the anonymity of the Internet. In contrast, they were

Henningsen provides an indication of differences in how flirting cues are perceived by men and women 
unable to find support for the compensation hypothesis, or the idea that people with low physical self-esteem or who are high in dating anxiety use online mechanisms for what they cannot do offline. In a survey of 1,017 Latino men seeking men (MSM) from the U.S., Ross, Rosser,

McCurdy, and Feldman (2007) asked open-ended questions about how men preferred to meet sex partners. They found three categories based on their coding: $48.4 \%$ declared "in real life" (IRL), 31.6\% said online, and 20\% indicated that "it depends" (Ross et al., 2007, p. 159). For the "it depends" category, thematic analysis revealed time, setting, mood, alcohol, drugs, sexual needs, and relationship intentions were all salient considerations.

Other studies reveal that sex is not limited to physical acts and can include rich forms of fantasy when it happens online. For example, a study with participants from the virtual world Second Life reports that they often engage in sexual activities there that they would not in the physical world (Craft, 2012). Further, participants pointed to the libratory

nature of Second Life and how it allowed them to engage in somewhat taboo sexual activities (e.g., anal sex, bondage) without social stigma. Similarly, Manning (2014b) found that sexting allows a space for adults to engage in fantasies they would not embrace offline. In another study of adult sexting practices, Manning (2013) conducted participant definitional analysis to learn that, based on how they talked about it, sexting was being constructed as

"the willing interactive exchange of sexual-oriented messages using a digital mobile communications device" ( $p$. 2510).

Based on this definition, he argues that when people discuss sexting it assumes that the sexual text messages were wanted; that the different types of messages viewed as being sexual-oriented can be wide-ranging and not always ostensibly about sex or sex acts; and that sexting is seen by those who participate in it as different from other forms of computer-mediated sexuality such as cybersex. Based on these results, he cautions online sex researchers to carefully consider the terms they use for representing participant behavior.

Even though sexting practices for adults did not seem problematic in the literature, Curnutt (2012) reviews several problems related to teen sexting and other forms of teen online sexual identity. Specifically, he argues that the ubiquity of social media have led to celebrities and teens using graphic sexual images (e.g., nudity, explicit sexual acts) in order to make up for what they see as undesirable qualities in themselves. He also questions whether sexting is more a way of reflecting on genuine sexual self or if it is a fast way to manage increased libidinal status. Lunceford (2011) also shares concerns about online adolescent sexuality, suggesting that laws have not caught up to teenage sexual behavior and that such behaviors must be considered to create fair and just laws. Another study of youths from across Europe (Smahel; Wright; Cernikova, 2014) indicates that they encounter many sexual problems online, including unwanted sexual requests and comments; sexual bullying; a pressure to publish sexual pictures to gain interest on social media sites; and revenge porn, the posting of personal sexual pictures or videos from an ex in order to evoke shame. Collectively, these adolescent-oriented studies suggest that only sexuality can be and often is more problematic for teenagers than it is for adults who face much less consequences.

Turning to another study of online adolescent sexual behaviors, Baumgartner, Valkenburg, and Peter (2010a) collected longitudinal data from 1,445 Dutch adolescents and learned that adolescents who engage online sexual behaviors perceive that more friends engage in such behavior; see less risks and more benefits to online sexual interaction; and feel less vulnerable about negative consequences. In a specific decision-making situation related to online sexual behavior, however, contextual factors -especially peer behavior- often resulted in a more-nuanced response from participants. Based on this finding, the researchers suggest more studies about peer influence regarding initiating and participating in sex online. In a different study, the same group of researchers (Baumgartner; Valkenburg; Peter, 2010b) compare the online sexual behaviors of adolescents and adults. Through a survey of 1,765 Dutch adolescents and 1,026 Dutch adults, they learned that adolescents are more at risk of encountering unwanted sexual solicitation online than adults, even if they did not engage in as much online sexual behavior. Again, a pattern of adults having less problems with online sexual interactions than youths emerges from the studies.

Adolescents are more at risk of encountering unwanted sexual solicitation online than adults

Finally, it is important to note that some studies about online sexuality looked less at initiating sexual interaction or relationships and more at maintaining them. As one notable example, Rubinsky (2018) examines the face-saving elements of negotiating sexual practices online for those who practice bondage, domination, and sadomasochism (BDSM). Similar to the sexting studies presented earlier in this section, she presents compelling evidence that many negotiations of sexual interaction happen via multimodal communication, with some communication about sexual wants, desires, and needs happening face-to-face and others happening online.

\subsection{Communicating pleasure and desire}

Many studies reviewed for this project focus on the pleasure people receive related to sexual communication as well as participants' sexual desires. Because these two concepts were often connected in the research used for this review, they 
are explored together here. The most common exploration of sexual pleasure in relationships manifested in the form of research about friends with benefits relationships (FWBRs). As one instance, in an essay that defines and explains FWBRs, Levine and Mongeau (2011) establish that FWBR sexual interactions are not one-time instances, but rather involve repeated encounters between two people. This conceptualization draws from a previous study (Bisson; Levine, 2009) that indicates that even though FWBRs allow trust, comfort, and sexual affordances without romantic commitment, rules are often not negotiated explicitly. Another study indicates that in many instances FWBRs do represent either an attempt at or a desire to shift from friendships to romantic relationships (Mongeau; Knight; Williams; Eden; Shaw, 2013). That same study also reveals 7 types of FWBRs. Four of these types represent an attempt for friends to transition a relationship from friendship to romance: successful, failed, and unintentional transformational relationships as well as relationships where the friend were transitioning out of the relationship completely; with the other 3 types being true friends, those who are seeking opportunity from their friend network, and those who just want sex.

Other studies about pleasure and desire are less cohesively connected to each other, with many of these studies appearing to be one-off works from the researchers. For example, Cowan and Horan (2014) found that coworkers perceived colleagues hooking up in the workplace as being about sexual pleasure and not so much about romance; and, further, that such relationships were often looked at with some level of disdain. Parker and Ivanov (2013) indicate that many women report discussing sexual wants and needs as being awkward in their first sexual relationships, but as they continue to experience sexual relationships there is more comfort to express what they crave or desire in a sexual interaction. Turning to methodology, Levine (2003) argues that the paradoxical nature of desire is not captured well in statistical research studies, especially pointing to how desire itself is not always wanted.

Still other studies connected sexual pleasure and desire to the spiritual. Woodward, Findlay, and Moore (2009) found in their study of 298 sexually active adults that about two-thirds of the participants had some sort of

“mystical sexual or loving experiences, feelings of sexual 'oneness' with a partner, intense passion or intense feelings of closeness and belonging, and out of the ordinary positive feelings such as overwhelming joy or happiness" (p. 436).

Such sexual-spiritual connections include mystical sex, where partners felt as if they were melding into one; sexual ecstasy and joy; a special sexual experience (e.g., being in the right time in the right place with the right person); or a sense of closeness and belonging. Lunceford (2009) also explores spirituality and sexuality, asking philosophical questions about whether increased mediation (i.e., computer-mediated or mobile communication) reduces the sacred experiences mentioned in Christian texts about two bodies becoming one.

\subsection{Communicating sexual expectations}

Studies about what people expect in terms of their interpersonal sexual interactions fall into two categories: sexual script studies and studies about dating. In a study about sexual scripts, La-France (2010b) takes a robust body of research from the 1990s about how sexual interaction and activity are learned and updates it for more contemporary times. First, she points out that because sexual scripts often begin in a public location, that specific location type could provide context as to whether or not sex is likely to happen. Second, she notes that sexual scripts often end with the sexual encounter, and although that is pragmatic for research, she argues it limits analysis by not including interaction during or after sexual intercourse. Finally, even though participants in her study indicate that the traditional sexual script is still realistic, she also believes that new research could examine in-depth how sexual scripts might have changed over time. This study is exemplary in the way that it continues to build knowledge via continued development of an already-established interpersonal sexual communication concept. More recently, La-France (2020) has argued that researchers must also consider unscripted sexual interaction, as most of the extant literature focuses on scripted interaction.

Returning to script research, another group of researchers examined first date scripts to, in part, understand how sex was or was not a part of expectations. In a first study, Morr and Mongeau (2004) investigate how three factors -relationship type, sex of initiator, and alcohol consumption- play into sexual expectations for a first date. The participants, 218 college students, read the same hypothetical scenario that detailed a dating situation. The study's findings indicate men have higher expectations about sex than women, but that most people expect more intimate communication when close friends are on a date versus a date between two people who are less familiar. When alcohol was introduced in the study as being available on the date, participants had higher expectations that sex would occur.

However, a second study (Mongeau; Morr-Serewicz; Ficara-Therrien, 2004) reveals alcohol as unexpectedly unrelated to sexual goals. Because the second study dealt primarily with date goals and constructing a first date, it might be that alcohol is not used as part of the planning for a date in order to achieve those goals. A third study that also explores dating goals (Mongeau; Jacobsen; Donnerstein, 2007) reveals that while college students might have differences for first date goals based on their reported sex, non-college students did not. More to the point of this review, college men tended to indicate sexual goals for dating whereas college women were more interested in friendship, having fun, and moving date-to-date. 
Emmers-Sommer and colleagues (2010) also conducted a dating study, this one with a specific focus on expectations about sex on a first date. Drawing from a pool of college participants, they found that men have higher first date sex expectations than women, especially when men pay for a date and the date occurs in an apartment (as opposed to a public place such as a movie theatre or restaurant). Interestingly, they also found that if a woman asked and paid for a date and the date happened in her apartment, then rape myth acceptance beliefs (i.e., the belief that rape is just a "myth" and does not tend to really happen) were higher for men in comparison to when men asked for and paid on the date or when either sex invited the other for the date and paid their own ways. Similar to the other dating studies, a focus on differences between men and women is in place -a recurring theme for research about interpersonal sexuality. Finally, other research -such as Coffelt's (2018) study on sexual goals, plans, and actions- examines the sexual scripts employ to delay or abstain from or delay sexual intercourse. Many similar studies of this nature fell more into the domain of safe sex communication.

\subsection{Communication as related to sexual and relational satisfaction}

Other interpersonal sexual communication studies explore aspects of satisfaction. For example, Coffelt and Hess (2014) found in their study of 293 married people that a positive relationship exists between disclosing sexual information and both closeness and relationship satisfaction. Two other studies reviewed for this project offer new measures of sexual satisfaction. In the first, Štulhofer, Buško, and Brouillard (2010) develop and biculturally validate a new sexual satisfaction scale, one with a particular focus on multiple domains of pleasure and that includes communication items. In the second, La-France (2010a) pulls from two theoretical models to develop a combined model that

Sexual communication is especially important to sexual satisfaction

uses sexual knowledge and sexual exchange variables to predict sexual satisfaction levels for individuals. Such development of scales or measures that explicitly and directly examine sexual communication are rare, based on this review, and researchers should continue to consider how they can develop similar tools.

In other studies related to satisfaction, Manning (2014b) found that adult couples could reduce uncertainty about what their partners did and did not want in terms of sexual interaction as well as increase their sexual satisfaction and pleasure through their sexting practices. That, in turn, bolstered their reported relational satisfaction. In a review of sexual satisfaction literature, Sprecher and Cate (2004) illustrate that sexual communication is especially important to sexual satisfaction. Such communication includes how sex is initiated, accepted, and refused; disclosure of both likes and dislikes; and communication involved with resolving sexual conflict. Theiss and Estlein (2014) found that sex topic avoidance and indirect sexual communication were negatively association with sexual satisfaction for women, but only sexual topic avoidance was negatively related with sexual satisfaction for men. In another study that focused more directly on sexual conflict (Rubinsky, 2021), those who are in marginalized relationships reported several sources of sexual conflict in their relationships, including gender dysphoria or a history of intimate partner violence.

Finally, Levine, Aune, and Park (2006) offer a particularly well-designed, unique, and complex study examining how love styles, among other things, are related to interpersonal sexuality -specifically in terms of relational intensification strategies. According to the study, those favoring ludic (spontaneous and playful) or erotic (sexual) love styles have the most unique attributes related to sex and sexuality. A ludic love style is positively related to physical attractiveness and being good in bed, although it is negatively related to intelligence and a good personality. It is also positively related to nonverbal affection and sexual intimacy. An erotic love style is also positively correlated with physical attractiveness and being good in bed, but unlike ludics, those with an erotic style are positively related to relationship satisfaction and stability.

\subsection{Communication after sex}

In an original and highly productive line of research, Amanda Denes and colleagues explore the communication that happens after sexual activity, frequently referred to as pillow talk. In a first study, Denes (2012) found that disclosure of positive feelings for a partner after sex is associated with relationship satisfaction, closeness, and trust; and, further, that women who orgasmed disclosed more than both women who did not orgasm as well as men who did. Additionally, this study suggests people in monogamous/committed relationships experience more disclosures following sexual activity and more positive outcomes in comparison to people in casual relationships. A second study (Denes; Afifi, 2014) adds alcohol to the equation, revealing that the more alcohol is consumed by an individual, that person will assess fewer benefits related to disclosing. Alcohol consumption was also related to less positively-valenced and less-deep disclosures; and the communicated disclosures were more unintentional.

Denes's pillow talk research extends to several areas of exploration including deceptive affectionate messages (Bennett; Denes, 2019), as it relates to uncertainty following a relational transgression (Denes; Crowley; Makos; Whitt; Graham, 2018), relational maintenance strategies (Denes; Dhillon; Speer, 2017), and difficult couple conversations (Denes; Crowley; Winkler; Dhillon; Ponivas; Bennett, 2020), among other topics. This robust line of research has led to the development of a Post-Sex Disclosures Model (Denes, 2018) that examines the connections between orgasm, self-disclosure, and relational satisfaction. Denes's work serves as a prime example of how a research program can be used to develop theoretical approaches to interpersonal sexual communication.

Disclosure of positive feelings for a partner after sex is associated with relationship satisfaction, closeness, and trust 
Examining a completely different form of post-sex communication and from a more philosophical angle is Lunceford (2008), whose study of the "walk of shame" points to how people treat the post-sex, morning-after walk home as a form of spectatorship. He notes that the teasing and taunting that accompany the walk of shame is particularly unkind to women and reflects sexist attitudes regarding sexuality. Finally, in a study that looks beyond the immediate after-sex period and more into the results of sexual activity, Manning (2014b) points to dyadic relational turning point interviews with couples to illustrate how sometimes first sex is also the first relational turning point. That is, for many couples in his study the first time they had sex -often moments after meeting each other- was considered by them to be the beginning of their enduring romantic relationship. This finding disrupts the common narrative that sex comes later in a relationship.

\subsection{Negative aspects of relationship-oriented sex communication}

I label the final relational category of interpersonal sexuality studies as the negative aspects of relationship-oriented sex communication. Although just about every interpersonal sexual communication topic has positive and negative aspects related to it, the topics listed here almost always deal with some sort of pain, aggression, and or psychological distress.

\section{a) Sexual coercion}

Few studies of sexual coercion were identified in the review; nor were there many interpersonal sexual communication studies about consent. The lack of consent research is especially surprising given that consent is ostensibly communicative and has been the focus of many news stories in recent years, especially in the U.S. In terms of consent topics related to interpersonal sexual communication, Kristen Jozkowski has developed a sophisticated and extended line of research that examines consent cues and how young adults decide whether or not a partner wants to have sex. Topics explored in her research program include competing definitions or understandings for what constitutes consent; cultural definitions of rape and consent; consensual unwanted sexual activity; and verbal consent cues, among others (for a complete overview see Jozkowski, 2016). The work she and her colleagues have conducted even calls into question such important aspects of consent such as how men and women see consent happening differently, including the locations/places and times where and when consent happens before sexual activity (e.g., Jozkowski; Manning; Hunt, 2018).

Other than Jozkowski's work, one other study examined the intersection of consent and ability. Specifically, Mandarelli et al. (2012) examined patients with either schizophrenic disorders or with bipolar disorder. Patients who were on the schizophrenic spectrum had a lower capacity to consent than did those with bipolar disorder. Poor cognitive functioning was associated with lower capacity to offer consent in both groups.

Moving more directly into the area of coercion, Jones and Olderbak (2014) found that men who scored higher in psychopathy and social dominance are willing to engage in coercive tactics for sex when presented with hypothetical scenarios that resulted in sexual rejection. Even if they did not score high in psychopathy and social dominance, men who scored high in narcissism were likely to engage in coaxing tactics to try and gain sexual compliance. In another study that connects to coercion, Nyanzi, Nyanzi-Wakholi, and Kalina (2009) frame cultural pressures for men to engage in risky sexual behaviors as a form of bullying that is dangerous to physical health and mental well-being. Again, the sexist and sometimes misogynistic expectations related to sexuality and culture are highlighted. Denes (2011) also embraced a critical approach in her study exploring the anonymously-authored book The mystery method: How to get beautiful women into bed where she describes how the book encourages men to see women's physiological responses as a problematic "truth" that they want sexual activity.

In terms of unwanted sex or sex-seeking attention, Koelsch (2014) examines the discrepancies between cultural discourses of sexual assault and the specific experiences of unwanted sexual relations as articulated by the women she interviewed. Her work indicates many women feel they do not have the agency to express their personal experiences on their own terms; and she suggests that sex not be labeled as either consensual or non-consensual, but that a continuum that uses "choice" and "force" be used. Afifi and Lee (2000) studied sexual resistance strategies, learning that identity/appearance goals strongly influence selection of strategies; concern for those goals diminish when a resistance plan fails; that the directness of a request might be limited immediately but becomes more relevant as resistance continues; and that more urgency is placed on women's sexual resistance responses than men's. Importantly, work has started to explore how women can be more assertive regarding sexual activity. For example, Widman and colleagues (2018) conducted a randomized controlled trial of an online program that helps adolescent girls to develop sexual assertiveness skills.

\section{b) Sexual harassment}

Other studies examine unwanted sexual attention in the workplace. Dougherty et al. (2009) make an interesting contribution to sexual harassment literature, using a new theory of language convergence/meaning divergence to explain 
how different parties in an interaction can use the same language to mean different things. This research helps to explain disjunctive beliefs in the workplace about whether communication is flirting or sexual harassment. In a more personal study, Johnson (2014) shares her autoethnographic story of sexual discomfort when, as a dancer in a music video, she was sexually demeaned. She specifically addresses her limited agency in the situation and considers how sexual memories are authored.

\section{c) Infidelity}

Two studies had a primary focus on sexual infidelity and what it means to relationships. Lunceford (2013b) complicates notions of infidelity, pointing to how online sexual interaction has always raised questions about what does or does not constitute cheating; but then also points to how developments in technology, especially advances in online robots (bots) could allow for interesting new forms of online sexual interaction. Donovan and Emmers-Sommer (2012) explored attachment and perceptions of infidelity, and as they expected found that women had better responses to men to a sexual infidelity scenario. Specifically, women, more than men, were likely to engage in constructive, integrative, and active response strategies. In terms of emotional infidelity, however, men responded in a more positive manner and were more likely to engage loyalty and passive constructive relational repair than were women. These results reflect a cultural idea that for men sexual activity is not necessarily linked to emotion and that men are more disturbed by their partners having sex with another than they are that partner spending time with another.

Reasons given for withholding past experiences: the past should be kept in the past; such information might threaten identity, especially if current lover is compared to past lovers; revealing such information threatens the relationship; and to avoid jealousy or embarrassment

Another study (Miller; Denes; Diaz; Buck, 2014) explored jealousy as it related to implied infidelity. The researchers found that hypothetical scenarios using online photos and vignettes generated significant emotional response; and increases of depiction of touch intimacy in photos caused these responses to heighten. Males also indicated more sexual arousal in response to seeing their partners interact with a friend, whereas females responded with fear, sadness, and envy.

\section{d) Privacy and surveillance}

Two studies feature negative aspects of privacy and interpersonal sexuality. First, Anderson, Kunkel, and Dennis (2011) investigated how couple members withhold information about past sexual experiences from each other. They learned that men and women displayed similar frequency in the four dominant rationales they offered for withholding such communication. The reasons include that the past should be kept in the past; that such talk might threaten identity, especiaIly in how the current lover might be compared to past lovers; that revealing such information threatens the relationship; and to avoid emotions such as jealousy or embarrassment. Using a queer-theoretical approach, Yep (2003) focuses on how sexualities labeled as queer or deviant might be labeled as such because they threaten notions of a public-private sexuality. As he asserts when writing about sadomasochism,

"By focusing on the entire surface of the body as a site of potential erotic pleasure, S/M practices challenge to dissolve the monopoly of genitally-focused sexuality -that is, penetrative sex encoded within the heterosexual matrix of meanings" (Yep, 2003, pp. 44-45).

In other words, he argues that reconceptualizing sexual activity threatens notions of what should or should not be exposed and what can be kept private. In response, cultures want people to hide non-normative sex.

In some instances, online communication can provide an outlet for sexual openness, and many times in positive ways. For example, Yeo and Chu (2017) offer an analysis of how Chinese college-aged students share "sex secrets" via a Facebook page. Their content analysis revealed that many participants in the group were seeking opinions or information $(30.38 \%)$ as well as making requests for advice $(13.68 \%)$. Most of the comments provided were supportive in nature $(69.49 \%)$, allowing a space where sex could be openly discussed. Such positive research is in contrast to the findings of Manning and Stern (2018) who point to how sexuality is both shamed online and often surveilled. That is, as people continue to be more sexual online, they risk being watched by others who will take the resulting online sexual artifacts (e.g., nude photos shared with a partner, sex videos) and share them with others. Their Theory of interpersonal panopticism accounts for how sexual interaction is controlled by the fear of being watched.

\section{e) Shaming}

Some of the sex education-oriented articles also framed sexual behavior, especially unsafe or frequent behavior, as a negative topic. In a review of narrative ethics, Adams (2008) points to the dangers of presuming that gay men are sexually irresponsible, promiscuous, or HIV+. He also points to the flaws of taking sex research that was created for one specific purpose and using it for another, such as someone who might cite a study of bathhouse culture as an example of how gay culture is morally "dirty" (Adams, 2008, p. 183). Finally, research about memorable messages (Gunning; Cooke-Jackson; Rubinsky, 2019) reveals several ways women are shamed for their sexuality, ranging from having sex while on their period to the fears they might have about fertility. 


\section{A review of health-oriented research about sexual communication}

Health topics presented here include research where interpersonal sexual communication is meaningfully addressed and studied/measured as part of the study but where the primary focus of the scholarship is on creating, maintaining, or preserving sexual health. Seventy-six of the 173 articles were sorted into these topic areas of sex education, sexual dysfunction, and negotiating safe sex practices.

\subsection{Sex education}

\section{a) Sex education/talk about sex in families}

The research corpus constituting the single-largest topic or subtopic in this study is sex education in families. Given that two state-of-the-art reviews have already covered the topic (see Coffelt; Olson, 2014; Wright, 2009), this finding is not surprising. Many of these studies focus on who is most likely to be part of conversations about sex, especially those that were educative in nature. For example, one study found mothers tend to offer more sex education, and when they do they tend to be more specific about the information they offer (Angera; Brookins-Fisher; Inungu, 2008). Another study indicates both mothers and fathers are likely to talk about sex with their sons, whereas mothers are more likely to talk with daughters (Wyckoff et al., 2008). In Raffaelli and Green's (2003) study of highly educated Latino young men and women, the young women reported more sexual communication with mothers than did the young men. They also reported Mothers tend to offer more sex education, and when they do they tend to be more specific about the information they offer sexual communication by young women was associated with non-Mexican origin. For those young women with older brothers in the home, there was also a negative association with sexual communication in the family. Finally, the study reveals more-educated mothers were more likely to talk with their sons about sex, with more-educated fathers likely to talk to both sons and daughters.

In his study of Israeli Jewish and Arab adolescents, Hetsroni (2008) found that the participants -similar to American teens in past studies- recognized television and peers as the most useful sources of information about sex. Parents were pointed to as less useful sexual information sources. In another study, Sprecher, Harris, and Meyers (2008) surveyed different groups of Midwestern college students on an annual basis for 17 years. They found students were turning to families on a consistent basis across the years; but that sources such as media, peers, and professionals were increasing in reliance as student sex education sources. A modest positive correlation linked higher social class index with a higher likelihood of American parents providing sex education; and, notably, Black participants reported significantly more sex education from parents in comparison with Whites and Latinos, with Latinos reporting the lowest amount of family sex education talk.

The prevalence of sex talk was also explored. Heisler (2005) found that most (77\%) of the participants from her study of 176 American student-mother-father triads could recall conversations about sexuality. Still, another study reflected that children often do not feel as if their parents are willing or able to talk about sex (Angera; Brookins-Fisher; Inungu, 2008). Some of the studies identified why sex talk is or is not happening. One of those studies found children who perceived their parents as having communication competence tended to be less avoidant about sex talk (Afifi; Joseph; Aldeis, 2008). Further, that study also suggested parents who were informal, receptive, and composed during conversations about sex had adolescents who reported being less avoidant and less anxious. The quality of the relationship was also an influential factor as to whether a child was anxious or avoidant during sex conversations.

Other studies examined parent openness during talk about sex. Kirkman, Rosenthal, and Feldman (2005) unpacked the complex meanings Australian parents held about being open with their children about sexuality. For those parents, openness included being willing to answer questions, even if they did not always maintain a spotlight on a question topic; being open-minded about what their children wanted to discuss; maintaining a sense of privacy boundaries; and taking a specific child's characteristics into consideration. Similarly, Coffelt (2010) found evidence that even if parents felt they could talk openly about sex because it is a natural topic, they also realized that some conversations could lead to challenges -especially depending on content. In a study drawing from Muslim Bangladesh participants, it was revealed that both inadequate parental understanding about sexual health and a lack of sex and relationship education from parents resulted in risk of infection or unwanted pregnancy for youths (Fernández; Chapman; Estcourt, 2008). In a different study, some women reported that parents indicated that abstinence should be maintained, but what constituted abstinence was blurry. Specifically, they believed some behaviors (e.g., oral sex) did not count as sex and, thus, were safe (Hertzog, 2008).

Research reflected some topics were minimized, avoided, or outright omitted. In a Thai study, results indicated parents were more likely to talk about body changes and dating and less likely to talk about more sexually-related issues such as using birth control (Rhucharoenpornpanich et al., 2012). Similarly, parents in the study who believed their children were sexually active talked about diseases or pregnancy instead of intercourse or when it might be appropriate to start having sex. Another study (Simpson, 2012) found that LGBTQ (lesbian/gay/bisexual/transgender/queer) relationships are often absent from sex education, including family conversations; and, further, parent-child sex talk often assumes heterosexuality. 
Other family sex talk was related more to sexual identity. In his study of LGB coming out conversations, Manning (2015a) found that some participants shared stories where they indicated their parents crossed the line with questions asked, including questions about whether a son participated in insertive or receptive anal sex or how two women could have intercourse. Based on these accounts, he suggests sensitivity to sexual privacy is important for parents to remember in these conversations. On a more positive note, in another study he found many participants appreciated when safe sex was mentioned -although they preferred for it not to be an immediate reaction to coming out or the main topic of the conversation (Manning, 2015b). In a third study, Manning (2014a) found that many families strongly suggested responsible sexual behavior for gay or bisexual men when they came out, going so far as to create rules about sex.

Baxter et al. (2009) learned that families tend to set rules about sexual activity for heterosexual children as well. Their study divides these rules into two larger categories. In one category is the abstinence-oriented rules that include not having sex before marriage; age-linked abstinence; preventative abstinence (e.g., "No being alone with boys"); and simple abstinence (e.g., "Do not have sex"). In the second category, they include five contingency-oriented rules under which sexual activity could happen: use of protection; in a close relationship; after discussing with parents; if it is what the child really wants (i.e., not feeling pressured); and specific to a particular location (e.g., "Not in our house"). The study also revealed that parents perceived more-direct communication and a greater sense of justification than adolescents reported, especially in terms of abstinence rules. Parents also believed that their children complied more with their rules than what was actually reported, again especially for rules about abstinence.

Another research program centered parent-child sex talks as they applied to purity pledges, vows children (usually girls) make to not have sex until they are married. Specifically, Manning (2015c) analyzed family talk about purity pledges and found that parents initiate such rituals because they want their children to have good lives; modern day sex is terrifying, but if saved for marriage can be a beautiful gift; and because girls have no sexual agency. In another study, he found that families seemed to be in synch about what purity pledges mean when they were being interviewed together (Manning, 2013); but when interviewed separately and away from family members, mothers often indicated they were introducing the pledges to their daughters out of loyalty to their husbands (Manning, 2013) or as a way of preventing their daughters from making the same sexual mistakes they did (Manning, 2017). In two other studies, he found that talk in these families covered both relationship and health aspects of sex (Manning, 2014b) and that the talks often examined social influences on sex such as oversexed popular entertainment (Manning, 2014d).

\section{b) Sex education in learning institutions}

When it comes to sex education in learning institutions, research from both the U.S. (Brooks, 2006) and the UK (Fernández; Chapman; Estcourt, 2008) indicate frictions between what cultures deem are appropriate and what educators feel they need to teach students about sex. Indeed, debates about sex education, including whether relational issues and/ or pleasure should be part of the sex education classroom, often exhibit a lack of shared ground about what should be covered (Brooks, 2006). Additionally, many sex education programs have access issues, with minorities being especially unlikely to receive formalized sex education (Fernández; Chapman; Estcourt, 2008).

Digging deeper into curriculum, Lieser et al., (2007) reviewed six different prominent pre-marital relationship programs to find that most do not spend much time exploring sexuality; and only four of them specifically addressed communication. The authors suggest that sexuality between non-heterosexual couples as well as cohabitating couples be included. Elia (2003) points to how textbooks about human sexuality often focus on how same-sex couples have the same intimate relational possibilities as heterosexual couples, reifying a hierarchy of sexuality. More directly related to the topic of this essay, he points to embedded notions in the texts that monogamous sexual relationships in marriage are the ideal status, excluding not only LGB people but those who cohabitate, are in open relationships, or even those interested in casual sex.

In terms of what participants want from sex education, Allen (2008) found both similar and additional critiques of sex education. Common complaints included that sexuality education is too clinical, de-eroticized, and moralistic; and participants craved more information about sexual pleasure, emotions and relationships, parenthood, and abortion. They also wanted to feel as if a program offered content that put them into a position to make informed decisions about their own sexual destinies. Similarly, in a large study of Irish youths, O'Higgins and Gabhainn (2010) found that the most dominant sex education desire was "how to establish healthy respectful, communicative relationships," demonstrating a desire for understanding interpersonal sexuality (p. 387). Finally, another study (Van-der-Stege et al., 2010) examined the use of board games as a form of sex education for adolescents with chronic conditions. Participants indicated they saw the games as beneficial for learning sexual health, demonstrating that sex education can be creative, enjoyable, and effective. 


\subsection{Negotiation of safe sexual practices}

As one might expect, many of the articles identified in this area involve negotiation of condom use. For example, Crowell and Emmers-Sommer (2000) examined the self-efficacy of college students and their sexual situation coping strategies. Even though students reported high condom efficacy, that still had a weak correlation with actual condom use. Further, students tended to use non-communicative coping methods, such as avoidance, rather than discussing safe sex with a partner. Those who did report using condoms regularly were also more likely to embrace communicative coping strategies. In another study, Juárez and Castro-Martín (2006) surveyed 678 sexually active male adolescents residing in favelas in Brazil. They found that education, HIV knowledge, and condom use during first sexual intercourse were significantly related to current condom use. Rinaldi-Miles, Quick, and LaVoie (2014) found that social proof, consistency, and authority were key principles of influence for decisions about condom use in casual sex encounters.

Wright, Randall, and Hayes (2012) use the Expanded health belief model as a mechanism for understanding condom assertiveness and college women. In their study, women who were condom-assertive tended to see themselves as more susceptible to sexual disease or infection, believed more in condom efficaciousness, had faith in the condom communication skills, believed condom assertiveness was tied to relational beliefs, understood their peers as more condom assertive, and planned to be condom assertive themselves. Other scholars criticized how both condom and safe sex studies in general were often aimed at women. Gavey, McPhilips, and Doherty (2001) particularly criticize this movement in sexuality research, pointing to women not always being fond of safe sex, especially involving condoms, themselves; the lack of control women actually have over condom use; and the propensity for many women to consent to unwanted sexual activity. They also point to how understandings of condom use are engrained in culture, and that cultural narratives about condom use do not necessarily empower women to negotiate safe sex. In fact, it might make them feel constrained.

Women report in another study (Parker; Ivanov, 2013) that the more experience they have with sexual relationships, the more comfortable they feel with bringing up topics such as contraception or refusing sex when a partner is unwilling to use protection. Further, although many women feel as if they understand the riskiness of unprotected sexual behavior, they also report that sex education does not prepare them for discussing those risks, as well as the protective steps that can be taken to avoid those risks, with their partners. In her discussions with Chinese women, Liu (2012) found that many women felt caught between cultural sexual scripts related to sex as a moral issue and sex as a health issue. As a result, this tension compelled many of the women to remain silent about sexuality. As a result, it is likely Chinese women will not only need knowledge about how to have safer sex, but they will also need education about how to negotiate safer sex.

Gender also plays a role in MSM (men who have sex with men) sexuality. As Haig (2006) found in his study of a community of gay men, it is often the idea that silence is constructed as masculine that prohibits negotiation of safe sex activity. Safe sex, especially the use of condoms, is also a highly-politicized topic for MSM, as Payne (2014) notes in his research involving the conflicting ideas about barebacking presented by professors Tim Dean and Leo Bersani. These discussions include questions about how safe sex campaigns control same-sex sexualities, minimize forms of intimacy, and continue to place family units and reproduction as a core concern. Political implications regarding safe sex can also be highly personal, as is reflected in Yeo and Fung's (2016) critical study of Chinese gay men that revealed being labeled as a 0 (docile, bottom) or 1 (assertive, top) impacted condom use. In a critical study of a different nature, Manning (2014a) learned from interviews with MSM that they were reluctant to share their sexual identities with physicians because, in part, they knew that they would be asked about whether or not they practiced safe sex, a question they believed was not typically asked of heterosexual patients. According to the study, gay or bisexual men were skeptical that straight men received as much attention around the area of safe sexual practices.

Masculinity was a key focus in a series of qualitative studies exploring interpersonal communication about sex conducted in Puerto Rico. In a first study, Noland (2006) found that machismo, changes in the role of virginity, and silence -for both men and women participants- limited meaningful sexual communication. Even if participants wanted to engage in sex talk, cultural notions of masculinity often hampered the initiative or ability to do so. In a second study (Noland; MacLennan, 2006), men and women participants critiqued flippant attitudes, the inability to create open and honest partner communication, and machismo as problematic for sexual relationships. These findings served as the foundation for a third study (Noland, 2008) where both meaningful communication about sex and abilities to negotiate safe sex were seen as limited by the male participants. Again, study participants pointed to machismo as well as messages received as a child about sex as reasons for their reluctance.

Another influence on safe sexual behavior found in the literature was optimistic bias. Chapin (2001) examined the connection between optimistic bias, the belief that sex is unlikely to lead to disease or pregnancy, and sexual risk taking for African American youths. His research confirmed that Black adolescents were more likely to have optimistic bias than their non-Black peers, and that this optimistic bias led to risky sexual behavior as well as mo-

Noland's study participants pointed to machismo as well as messages received as a child about sex as reasons for their reluctance to speak about it 
re-permissive attitudes about sexual intentions. As a final note, one research study frames sexual communication in a unique way. Specifically, Horan (2016) found that people often disclosed the accurate number of past sexual partners to a current sexual partner as a way of enacting safe sex communication and ensuring that sexual history is accurate before engaging sexual activity.

\subsection{Sexual dysfunction}

Four studies related to sexual dysfunction were also identified in the research. The sexual dysfunctions related to depression were explored in a qualitative research study by Knobloch and Delaney (2012) that masterfully examined the intersections of health, relationships, and sexuality, among other topics. The study found that questions regarding physical intimacy were a part of the relational uncertainty couples struggling with depression faced. In revealing this relational uncertainty, the authors share participant accounts of how sexual problems related to overall relationship qualities. No other studies discussing sexual dysfunction were identified for the review, although in a review of the book Coping with premature ejaculation: How to overcome PE, please your partner, \& have great sex Ren (2007) notes that the text uses outdated language such as the titular term "premature ejaculation" rather than the more-current "ejaculatory control" (p. 475). The review author also critiques that the book assumes those suffering from ejaculatory control issues are in a relationship, thus dismissing masturbation as a possibility. On a more positive note, she indicates that the book highlights the value of interpersonal communication as it relates to sex.

Finally, in a more-recently developed research trajectory, Hintz $(2018,2019)$ explores vulvodynia and its impact on sexual relationships. This work is directly related to interpersonal sexual communication, as it examines the implications that the inability to have painless intercourse has on both their relationships and their women-centered identities. The studies offer practical implications, including three communicative strategies for managing vulvodynia-oriented dilemmas: reframing illness in conversation, refocusing how the relationship is articulated, and redefining intimacy. The work also calls into question what constitutes normal heterosexual sex.

\section{A review of culture-oriented research about sexual communication}

For the next section of this review, I provide an overview of literature that is culture oriented. Although many of these studies might be directly related to relationships or health, they are distinct in that they are weighted more toward impacts on interpersonal interactions as opposed to being a direct observation of interpersonal interactions. Two categories are presented in this section of the review: social influences on sexual communication and media representations as they directly impact or portray interpersonal sexuality.

\subsection{Social influences and factors on sexual communication}

Many studies examined for the review explore how elements in cultures or societies influence or control interpersonal sexuality. For example, based on his study of Arab adolescents, Hetsroni (2008) speculates that the conservative nature of some societies are related to teens being more satisfied with family and other interpersonal or professional information sources about sexuality because the baseline knowledge would be so low that even the most minimal of information would be viewed as valuable. He also found that boys were more likely than girls to turn to the Internet about sex, but that might also be related to boys' overall greater use of the Internet than girls. Similarly, Noland (2010) argues that researchers have neglected interpersonal communication about sex, thus causing a gap in academic discourses that, in turn, create a gap in cultural discourses. She and her colleagues (MacLennan, Manning, and Noland, 2010) also make arguments, based on a review of sexual communication literature, that personal elements of sexuality are often obfuscated or minimized in cultural discourses of romance or relationships.

Other researchers focused on how culture allows or disallows a sense of agency. Egan and Hawkes (2009) make an argument that the sexual agency of children is under-recognized, and that this approach to sexuality is perhaps focusing too much on protecting children instead of helping them to become fully realized sexual beings. Adams (2011) draws from personal experience as well as participant interviews to articulate how cultural notions of the closet disallow queer people both the ability to articulate their identities without punishment as well as feeling that their sexual behaviors are their own. Mahdavi (2009) examines the current sexual revolution happening in Iran, noting that youths are engaging in more sexual activity even though punishments -including lashings or even public execution- are still part of the law.

Studies also examined college campuses and the sexual cultures they create. Koelsch, Brown, and Boisen (2012) argue that college party environments create a risk for unwanted sex but, given the number of people in a party situation, might also provide a group of people who can intervene when risk occurs. This opportunity for intervention is limited, however, as members of their focus groups indicated that most sexual behavior is probably happening behind closed doors. Lannutti and Denes (2012) also consider sexuality on college campuses, with a focus on the fetishization of woman-woman kisses. Based on their survey of 164 college students, they found that men saw woman-woman kissing as atypical, at least more so than women. A woman kissing a woman was seen as more "promiscuous" than a woman kissing a man, and a woman kissing a woman was also seen as more likely being heterosexual than lesbian or bisexual.

Researchers have neglected interpersonal communication about sex, thus causing a gap in academic discourses that, in turn, create a gap in cultural discourses 
Other studies focus more on the control of sexuality, especially through language. Adams (2009) explores how language and discourse reflexively relate to sexual identities and practices. In his essay, he unpacks a slur that was yelled at him while walking. In addition to exploring the slur's violent implications, he also considers how the phrase relates to "Your mama" jokes; how these jokes invoke notions of a younger man sleeping with a sexless, undesired older woman; and how it assumes that the receiver of the slur desires women and wants to have sex with them. In another study exploring sexual identity, Manning (2015d) found that gay or lesbian people were often told they needed to try sex with an opposite-sex partner before they could confirm their sexual identities. In a different study (Manning, 2014a), he found that immediate surroundings, such as religious imagery or indicators of a conservative political nature, influenced what sorts of sexual behavior gay men would discuss -especially in family homes and medical settings.

Although it does not focus on social control, another language-focused study (Peck et al., 2016) examines what, exactly, people mean when they use the term "had sex." Drawing from surveys completed by adults in the U.S., the study reveals that some people, especially those who are older, would say they had sex if the most sexual activity they had engaged was open-mouthed kissing. As might be expected, people were more likely to not claim they had sex with activity such as penile-anal penetration or oral sex, with men generally claiming more activity as having had sex than women. Also as expected, the most selected sexual activity that participants counted as having had sex is penile-vaginal intercourse.

Other research focused on the contributions of online culture to interpersonal sexual communication understandings. For example, Lunceford (2013a) examines how particular sex behaviors are articulated in cultures, especially via online media, to create a sense of notoriety. Through his analysis of sex acts including the Donkey Punch, the Cleveland Steamer, and the Houdini, he identifies three categories of sex acts: scatological acts, humiliating acts, and violent acts. In another study, Holman and Sillars (2012) examine how social networks encourage high-risk sexual relationships among college students, especially in terms of hooking up. In addition to findings related to sexual health, they discovered that students tended to overestimate how much others were hooking up. Other hookup research (Kratzer; Aubrey, 2016) indicates men see little difference between their ideal and actual hookups; whereas women had "very different" actual experiences in contrast to their ideal scenarios (p. 236).

\subsection{Media influence and representations of sexual communication}

Other studies embraced critical humanistic approaches to consider what popular texts have to offer constructions of interpersonal sexuality. In one of these studies, Kgafela (2007) contrasted the male persona found in Barolong Seboni's love songs and how their sexual freedoms, including descriptions of sexual acts, were in contrast to the sexuality of women who were controlled by men and left to no sexual adventure or excitement. Amaya and Blair (2007) praise the films $Y$ tu mama tambien and Muchacha as progressive texts that critique traditional sexualities and allow for space to develop new masculine friendships, including shared physical sexual expression, in Latin America. Eguchi, Calafell, and Files-Thompson (2014) note that queer people of color are rarely portrayed in film before critically analyzing a Black same-sex relationship in the film Noah's Arc: Jumping the broom. This critique particularly examines portrayals of monogamy and sexually transmitted deseases (STDs) in the film, and how they might construct notions about Black same-sex sexuality. Finally, Manning (2011) compares the television programs The bachelor, Flavor of love, and Boy meets boy to examine the sexual liberties white straight, Black straight, and white gay men, respectively, are allowed to take or not take as part of reality television. His analysis notes that straight white men are presented as gentleman, with sexual behaviors happening behind the scenes; Black men are portrayed as hypersexual and aggressive; and gay white men are not allowed to be portrayed as sexual at all, with more of a focus on romance or even cross-sex friendship.

Other studies were more empirical in nature. Bond (2014) used content analysis to quantify sexual messages in a sample of music, films, television programs, and magazines popular with LGB youth. He found that LGB representation was underrepresented compared to heterosexuality and that LGB sexual talk was often based on stereotypes or insults related to sexuality and not relationships or sex. In a follow-up study (Bond, 2015) that focused specifically on gay- and lesbian-oriented media, he found that those sources depicted a diverse array of LGB relationships as well as diverse sexual interests and behaviors. As he noted, these portrayals were more realistic than what was found in mainstream media. Similarly, another study (Aubrey et al., 2020) examining the heterosexual script on young-adult television programming found that the dominant heterosexual script is sex as masculinity (among other findings).

In another content analysis study, this one examining articles about sexuality and relationships from a year of Cosmopolitan magazine, $52 \%$ of the articles suggested women were responsible for a man's sexual pleasure, $29 \%$ suggested women were responsible for their own sexual pleasure, and only $18 \%$ suggested both men and women were mutually responsible for pleasure (Gupta; Zimmerman; Fruhauf, 2008). The articles analyzed for the study often included specific actions and sayings for women to use in sexual situations. The authors also found that the magazine offered other forms of relational advice that were stereotypical and that assumed heterosexuality. Gupta and Cacchioni (2013) also found that manuals aimed at improving sexual interaction are now focusing on a new discourse of "sex as health," adding a new form of sexual pressure to what they characterize at the "growing pressure to master, improve, and work on sex" (p. 442).

Research indicated popular media acted as an informant for sexual beliefs 
Research also indicated popular media acted as an informant for sexual beliefs. Comella (2013) found that discourses surrounding the popular book Fifty shades of $G$

rey were informing people's understandings of BDSM. Similarly, Manning's (2014d) study of purity ring families demonstrated that parents used popular culture as an indicator of cultural sexual beliefs and behaviors and as an informant about what issues they should address with their families. Finally, looking at a different way that media texts inform sex lives, Daneback, Træen, and Månsson (2009) used questionnaire data from 398 heterosexual couples to examine how pornography was used to enhance their sex lives. They found that $77 \%$ of the couples reported no pornography use, $15 \%$ reported that both had used pornography, in $5 \%$ of the couples only the man and in $3 \%$ only the woman had used pornography. The same study suggested couples where at least one used pornography had a mo-

Sociopsychological approaches were the most commonly used theoretical approach to the studies collected for this review re-permissive erotic climate compared to those that did not. When only one partner used pornography, it was often associated with arousal problems (men) or self-perception issues (women).

\section{Metatheoretical approaches to sex and relationship studies}

As a response to the literature summarized in sections 2-4, and in answering the second guiding question for this project, I now consider the theoretical commitments that interpersonal sexual communication studies embrace. To sensitize myself to this endeavor, I have reviewed past research about theoretical traditions in the communication discipline (e.g., Craig, 1999; Craig; Muller, 2007) as well as theoretical traditions common to interpersonal communication studies (Manning, 2014c). Not surprisingly, and similar to other areas of interpersonal communication research, sociopsychological approaches were the most commonly used theoretical approach to the studies collected for this review. Critical perspectives were also extensively used by researchers, and even though that is not typically the case in interpersonal communication studies the finding was not surprising given that critical approaches are quite common in sexuality studies (see Manning, 2014b). In particular, feminist or queer approaches were especially used, sometimes in conjunction with rhetorical theory or other non-social scientific methods. The only other theoretical traditions to gain much traction were sociocultural approaches and biological approaches. Table 1 features an overview of the dominant metatheoretical approaches found in the review of literature as well as defining characteristics of each tradition as they apply to interpersonal sexual communication studies.

Table 1. Metatheoretical overview of interpersonal communication studies about sex and relationships

\begin{tabular}{|c|c|c|c|c|}
\hline Tradition & $\begin{array}{c}\text { Communication } \\
\text { as... }\end{array}$ & $\begin{array}{l}\text { Interpersonal } \\
\text { metadiscursive } \\
\text { vocabulary }\end{array}$ & $\begin{array}{l}\text { Intellectual } \\
\text { interests }\end{array}$ & $\begin{array}{l}\text { Sample topical, conceptual, or } \\
\text { theoretical manifestations from } \\
\text { this review }\end{array}$ \\
\hline Sociopsychological & $\begin{array}{l}\text { Interaction, influence, } \\
\text { and expression }\end{array}$ & $\begin{array}{l}\text { Effect, behavior, variable, } \\
\text { emotion, perception, } \\
\text { personality, attitude, } \\
\text { cognition, interaction }\end{array}$ & $\begin{array}{l}\text { Communication reflecting } \\
\text { personality; beliefs, feelings, } \\
\text { judgments, and bias; hu- } \\
\text { mans as rational; perception }\end{array}$ & $\begin{array}{l}\text { - Safe sex communication (e.g., Li; } \\
\text { Samp, 2019) } \\
\text { - Sex as expectation (e.g., Em- } \\
\text { mers-Sommer et al., 2010) }\end{array}$ \\
\hline Critical & $\begin{array}{l}\text { Reflection on } \\
\text { discourse }\end{array}$ & $\begin{array}{l}\text { Resistance, individua- } \\
\text { lism, dialectic, ideology, } \\
\text { paradoxes, consciousness, } \\
\text { emancipation, historicity }\end{array}$ & $\begin{array}{l}\text { Distribution or circulation } \\
\text { of power; awareness and } \\
\text { insight; questioning of ob- } \\
\text { jectivity; sites of knowledge; } \\
\text { freedom, reason, equality }\end{array}$ & $\begin{array}{l}\text { - Heteronormativity (e.g., Adams, } \\
\text { 2011) } \\
\text { - Sexual consent (e.g., Koelsch, } \\
\text { 2014) }\end{array}$ \\
\hline Sociocultural & $\begin{array}{l}\text { Negotiation/ } \\
\text { production and re- } \\
\text { production of social } \\
\text { reality }\end{array}$ & $\begin{array}{l}\text { Performance, culture, } \\
\text { identity, negotiation, } \\
\text { stories, rules and rituals, } \\
\text { sensitization, socialization, } \\
\text { co-construction }\end{array}$ & $\begin{array}{l}\text { Negotiation of identity in } \\
\text { society; social actions; social } \\
\text { construction of reality; } \\
\text { meaning-making through } \\
\text { interaction }\end{array}$ & $\begin{array}{l}\text { - Sex and aging (e.g., Manning; } \\
\text { Adams; Atay, 2020) } \\
\text { - Peak experiences in relations- } \\
\text { hips (Woodward et al., 2009) }\end{array}$ \\
\hline Biological & Genetic & $\begin{array}{l}\text { Brain and behavior, } \\
\text { hormones, genetics, evo- } \\
\text { lution, physiology }\end{array}$ & $\begin{array}{l}\text { Relationship between hu- } \\
\text { man behavior and genetic } \\
\text { influence }\end{array}$ & $\begin{array}{l}\text { - Oxytocin and post-sex talk (e.g., } \\
\text { Denes, 2012) } \\
\text { - Affection exchange theory and } \\
\text { sex (e.g., Horan, 2016) }\end{array}$ \\
\hline
\end{tabular}

As the table illustrates, theoretical variety in interpersonal communication studies of sex is limited, especially considering the field of communication studies writ large has at least 12 different theoretical traditions (see Craig; Muller, 2007). This lack of paradigmatic diversity is explored more in-depth in the final section of this review where I explore areas for growth.

\section{Continuing the momentum: Areas for growth and development}

Drawing from both the typology of research studies presented in this review and the metatheoretical inclinations presented in the previous section -and in line with the third guiding question for this review of scholarship- the final segment of this essay focuses on how interpersonal communication scholarship about interpersonal sexual communication could develop to make the most of the limited momentum that has been gained over the past two decades. I specifically 
focus on five problems related to interpersonal sexual communication research: missing research foundations, a lack of methodological innovation, heteronormativity in sexual communication research, a lack of meaningful findings and/or theoretical development, and evading sex in sexual communication research.

\subsection{Establishing research foundations}

One of the most startling aspects of this literature review is how few researchers have ongoing programs related to relationships, sexuality, and interpersonal communication that could be discovered via the methods used for this article. Although the methods for this review are limited in that they do not explore the totality of interpersonal sexual communication research -as many communication studies about sex are published in non-communication field journals and other disciplines are certainly doing research about sexual communication- it is still disheartening that so little sex research is making it into the core disciplinary research database. For many of the scholars cited here, it was one-studyand-done in terms of their contributions. Some of the scholars had additional conference papers about interpersonal sexuality (per the Communication and Mass Media Complete database or as discovered via Google Scholar), and so it is not necessarily the case that this research is not being done or a program continued. It is evident, howe-

\section{Sex scholarship does not always receive respect in the communication discipline}

ver, that not all of this research is being published. The reason for this might be that sex scholarship does not always receive respect in the communication discipline (Comella; Sender, 2013); or it could be that many sex researchers are not at universities that are research-intensive in terms of their mission. It could also be because the research is of a low quality and not suitable for publication.

Regardless of reason, and given the importance of sex and sexuality to most people's everyday lives, support for sex research in the communication discipline is essential. The lack of interpersonal sexual communication research programs also means few models exist for emulation. As an exercise in considering where traction is being gained, I present here a table with researchers who, based on the methods used for this review, have achieved 5 or more total publications related to interpersonal sexual communication since 2000 (see Table 2). Nine different scholars were identified, a small number considering that inclusion in the table represents an average of about one publication every four years covered in this review. In other words, research about interpersonal sexual communication is being produced slowly by those who are continuing to do such work. That being stated, three of the scholars (Denes, Manning, and Rubinsky) had five or more articles in the past five years alone; and all three of these researchers earned their Ph.D. in 2006 or later. Their productivity indicates that recent research programs might be producing research more quickly as well as receiving more support both from the field and their research institutions.

Table 2. Researchers with five or more publications about sex and interpersonal communication, 2000-2020

\begin{tabular}{|l|l|l|}
\hline \multicolumn{1}{|c|}{ Researcher } & \multicolumn{1}{|c|}{ Most recent affiliation } & \multicolumn{1}{c|}{ Research area(s) } \\
\hline Amanda Denes & University of Connecticut & $\begin{array}{l}\text { Pillow talk; infidelity; orgasm authenticity; perceptions of sex and sexuality; phy- } \\
\text { siology }\end{array}$ \\
\hline David D. Henningsen & Northern Illinois University & Flirting \\
\hline Kristen Jozkowski & Indiana University & Consent \\
\hline Betty La-France & Northern Illinois University & Sexual scripts; social-sexual interactions; self-disclosure \\
\hline Brett Lunceford & Independent Scholar & Sexual ethics; the implications of media on sexual relationships \\
\hline Jimmie Manning & University of Nevada, Reno & $\begin{array}{l}\text { Purity rings; sexting; coming out; consent; sexual harassment; surveillance; aging; } \\
\text { methodology }\end{array}$ \\
\hline Paul A. Mongeau & Arizona State University & Dating; friends with benefits; alcohol use and sex \\
\hline Carey Noland & Northeastern University & Talk about sex; sex and sexuality in Puerto Rico \\
\hline Valerie Rubinsky & University of Maine at Augusta & Memorable messages about sex; BDSM; sexual and gender minorities \\
\hline
\end{tabular}

The range of research covered in these scholars' programs as well as their diverse theoretical and methodological approaches is also heartening. Rhetorical (Lunceford), semiotic (Lunceford), phenomenological (Manning), sociopsychological (Denes; Henningsen; Jozkowski; Mongeau; Rubinsky), sociocultural (Jozkowski; Manning; Noland; Rubinsky), critical (Denes; Lunceford; Manning), cybernetic (Manning), and biological (Denes; Henningsen) traditions or approaches were represented in their work, with many scholars crossing over into multiple traditions or blending more than one tradition in a single study. Still, one common element among all of these researchers is that they are limited in how they conceptualize sex in their studies. Most are looking at sex indirectly or in hypothetical scenarios.

Moving beyond the most prolific researchers in the review, it is also important to note that many of the scholars who authored only one study came from disciplines other than communication or media studies. These fields or disciplines include sociology, women's studies, education, family studies, English, anthropology, and others. That suggests that conceptual and theoretical work in the communication discipline might come from exploring other-disciplinary work. It is also important to note that some scholars within the communication discipline who have one or more studies in this review have also studied other topics related to sexuality but that did not meet this review's rules of inclusion. Nota- 
ble examples include Tony E. Adams and Michaela D. E. Meyer who have written many academic essays about sexual identities; Tara M. Emmers-Sommer, who has a rich research history in the area of sexual health; and the duo of Patti M. Valkenburg and Jochen Peter who have a high-impact research program involving online sexuality. Sociologist Susan Sprecher and public health scholar Laura Widman also have extensive research programs related to interpersonal sexuality that crosses into communication topics and concepts. Their work -and the work of others- might serve as inspiration for interpersonal communication work directly related to sex.

That being stated, it is also notable that the scholars identified here are all white and from the U.S. Those who do sexual interpersonal communication research should consider how they can make their topical area of the field welcome to scholars of color and from across the world.

\subsection{Developing research methods and approaches}

This review also reveals that the typical quantitative/qualitative disparity that favors postpositive perspectives in interpersonal communication studies (see Braithwaite; Schrodt; Carr, 2015) is not so evident in this body of studies. This result is partially due to the constitutive philosophy and methods guiding this review; but it is also only possible because researchers are embracing a wider range of methods for their work. That does not mean that scholars cannot continue to push forward with methodological innovation in studies of sex and relationships. As Manning and Kunkel (2014a) note, qualitative interpersonal relationship studies tend to rely too much on thematic analysis in lieu of more sophisticated interpretive-analytical approaches. Many of the articles reviewed for this study fell prey to the limitations of thematic analysis. One possible reason for this might be the difficulty of constructing a literature review about interpersonal sexuality topics. Research about interpersonal sexuality is spread across many disciplines as past reviews (e.g., Sprecher; Christopher; Cate, 2006) and this review itself suggests. Given this spread, and the aforementioned lack of research foundations in interpersonal communication studies, it could be more difficult to iteratively consider the emerging qualities of qualitative data by using existing research as a heuristic. That, in turn, might limit what the data can say about the topic of focus. This concern also applies to quantitative studies.

Moving to another observation, many of the quantitative studies reviewed in this essay lend themselves well to qualitative follow-up studies. For example, in La-France's (2010b) study about sexual scripts -a topic that in many ways lends itself to both postpositive and interpretivist theorizing- she suggests that the nuances of contemporary sexual scripts be explored, even if those sexual scripts follow the same general pattern of existing scripts. Interpretive qualitative methods could be especially useful for collecting such descriptive data and then tying it back to the quantitative studies or -even more likely, given the revelations often made during iterative analysis of qualitative data- create new, sophisticated, and potentially exciting theories or concepts related to sexual scripts. Relatedly, few of the studies reviewed used mixed methods, and only one (Ross et al., 2007) used mixed methodology in its truest sense (see Cresswell, 2014). More specifically, even thought multiple methods were used by researchers for a single project, none of the studies took advantage of mixing postpositivist and interpretivist paradigms to develop sets of data that could be analyzed together to create multivalent and mutually-informative findings.

Interpersonal sex researchers should also continue to explore how to develop methods that will accurately reflect the people and cultures engaged in their studies. It is important that as this work is done, it is considered that situations and contexts change over time. As Sprecher, Harris and Meyers (2008) note, few studies about sex and sexuality are conducted in ways that foreground or even recognize changing attitudes and cultures. These changes should be considered during theorizing. The addition of longitudinal studies would also be illuminating both for understanding how people and cultures change but also for putting studies into context when being reviewed, translated for practical use, or when being considered in conjunction with the design of a new study.

Finally, those who are newer to interpersonal communication studies of sex and relationships can turn to multiple sources in order to consider how they might go about doing their work. Comella and Sender (2013) talk about many of the political challenges associated with doing such work, and their perspective is particularly useful for critical scholars who embrace humanistic approaches to scholarship. Denes (2013) offers a candid reflection on her challenges of researching post-sex communication, detailing many aspects of her quantitative work including research design, participant recruitment, and explaining her studies to others. Manning (2013) details how he developed two new qualitative analytical tools to do research related to sex, and he also offers advice for promoting qualitative work, especially to scholars who misunderstand its advantages.
Even thought multiple methods were used by researchers for a single project, none of the studies took advantage of mixing postpositivist and interpretivist paradigms to develop sets of data that could be analyzed together to create multivalent and mutually-informative findings 


\subsection{Eliminating heteronormativity in sexual communication studies}

This review of literature also exposes just how common heteronormative values and assumptions are exhibited in interpersonal sexual communication scholarship. Perhaps most notably, many studies are focused on gender differences. Specifically, many studies gravitate toward the idea that men behave one way and women another when it comes to interpersonal sexuality; and then also that men are attracted to women and women are attracted to men. On a deeper level, many of the studies carry values aligned with heterosexual monogamy; and, further, the research, even when conducted from theoretical and methodological stances that value objectivity, use words such as "promiscuous" to describe sexual behavior. Such heteronormative values and assumptions have been noticed more generally in communication studies (see Manning et al., 2020) and especially in interpersonal and family communication studies (see Chevrette, 2013; or Foster, 2008). It is evident that even when scholars are attuning themselves to human sexuality as part of their communication research, they are still embracing heteronormativity; and that, in turn, has an impact on how identity is situated in such research.

Moving forward, sex researchers must consider sex beyond heteronormative domains. That also includes considering that sex is, many times, simply be for pleasure and does not involve negative aspects; that many diffe-

\section{Sex researchers must consider sex be- yond heteronormative domains}

rent forms of sexual relationships exist, including in gender-diverse partnerships and polyamorous relationships, among others; and that even as individuals enact in sex those actions are embedded in particular personal and social relationships as well as cultural practices and knowledges. In other words, sophisticated thinking about sex and its implications is called for when it comes to interpersonal sexual communication research.

One way to combat closed-mindedness and judgmental sexual research is to embrace more of the tenets of queer theory. Simply put, queer theory is a body of theory that examines cultural expectations regarding genders and sexualities and how such expectations are limiting and/or harmful to those whose sexualities are perceived as different. Although queer theory is primarily used to explore LGBT sexualities as well as the experiences of other sexual and gender minorities, it is also a beneficial tool for understanding sexual acts and identities that are more heteronormative in nature. For a deeper consideration of how queer theory can be applied to interpersonal sexual communication research and theorizing, see Manning (2020) or Manning and Adams (in press).

\subsection{Focusing on applied understandings and practical theory}

At its best, interpersonal communication studies of sex and relationships can answer important questions with helpful research findings that lend themselves to the development of informative theories. One excellent example of this is Dougherty et al.'s (2009) exploration of workplace relationships and how behaviors that one person believes are flirting could be perceived as sexual harassment by another. The resulting theoretical development of language convergence/ meaning divergence not only informs interpersonal communication studies of sex and communication but creates a theory that can be used or tested in other contexts where meaning about cues can be disjunctive. In short, the study offers a new, helpful theoretical explanation for what is happening about sexual communication that, in turn, informs a big problem that plagues many workplaces and has ideas that are transferable to other studies. Although it is true that every study cannot develop a new theory or help to solve sexual problems to this extent, it would be ideal if all studies could embrace possibilities for helping people with their sexual problems, both big and small in some way.

Big problems that lead to big research questions about interpersonal communication and sex are frequently featured in news and popular culture, but as this review indicates many of those problems or questions are not being addressed or answered. For example, even though some scholars have looked at issues of sexual consent -a topic that is directly related to interpersonal communication- few studies were identified that examined consent. For those that were identified, none examined what did or did not constitute consent, how consent could be approached in sexual relationships, or how or why consent was seen as confusing. One way to develop positive recognition for interpersonal studies of sex is to embrace -and perhaps use research to solve- big questions about sex and relationships. Yet, at the same time, some of the basic problems associated with interpersonal sex are missing as well. Where are the studies that explore how to communicate about sexual pleasure in bed? Why are there no studies that suggest how people might introduce fantasies to sexual partners? What about research that examines how a partner responds when he prematurely ejaculates?

\subsection{Theorizing sex as communication}

Looking across the 88 articles reviewed for this essay, it is apparent that although the authors of each are asking important questions about sex in their own right, it is not always apparent what sex is and what these multiple iterations of sex have in common. When examining the ideas and concepts surrounding sex, the waters become even muddier. For example, in his critical essay about using research about desire in the clinic, Levine (2003) laments how,

"researchers must simplify desire in order to measure it," especially because it is a "slippery concept" (p. 279).

Sex research, and interpersonal communication research in general, is filled with such slippery concepts. One of the reasons a discourse approach to thematic analysis was used to sort and describe the research included in this review was to examine how similar ideas might work together. For example, the terms relationship satisfaction and sexual satisfaction 
have a particular meaning for many quantitative researchers, but in honoring participant voices many qualitative researchers write about these forms of satisfaction in a different way and with different meanings.

Although there is certainly value to having rigid understandings of what, exactly a term such as relationship satisfaction means in terms of social scientific research -after all, a clear conceptualization avoids the slipperiness of such a termthe locking in of this idea means that lived elements of slipperiness are deflected, minimized, or erased. To avoid such emotional or perceptual erasure, and to promote the different ways people see and experience concepts related to sex and relationships, I return to the idea introduced at the beginning of this essay: As scholars forge ahead with interpersonal communication studies of sex and relationships, it is important that theories, concepts, and applications remain constitutive. In presenting topics from across research paradigms and theoretical traditions, I have tried to combine sometimes disparate ideas to consider how researchers of sex, relationships, and communication, might view and learn from each other's work.

Given that purview, I close with a final challenge for interpersonal sex scholars. Given that a review of 20+ years' worth of interpersonal communication studies about sex and relationships did not yield a single article that theorizes sex as communication, I submit a series of questions that scholars in the area should take seriously: How can interpersonal communication scholars study sex as communication? What does sex mean? What is its symbolic value? I ask these questions not only in terms of sex as an abstract idea, but also in consideration of it being a physical and/or mental act. How does sex serve as communicative interaction? What messages are involved? What does sex mean to relationships and interpersonal communication? Finally, what does answering these questions mean to the totality of work in this area? What happens to interpersonal communication studies of sex and relationships then?

This review of $20+$ years' worth of interpersonal communication studies about sex and relationships did not yield a single article that theorizes sex as communication

\section{References}

Adams, Tony E. (2008). "A review of narrative ethics". Qualitative inquiry, v. 14, n. 2, pp. 175-194. https://doi.org/10.1177/1077800407304417

Adams, Tony E. (2009). "Mothers, faggots, and witnessing (un)contestable experience". Cultural studies - critical methodologies, v. 9, n. 5, pp. 619-626.

https://doi.org/10.1177/1532708609339488

Adams, Tony E. (2011). Narrating the closet: An autoethnography of same-sex attraction. Walnut Creek: Left Coast. ISBN: 9781598746204

Afifi, Tamara D.; Joseph, Andrea; Aldeis, Desiree (2008). "Why can't we just talk about it? An observational study of parents' and adolescents' conversations about sex". Journal of adolescent research, v. 23, n. 6, pp. 689-721. https://doi.org/10.1177/0743558408323841

Afifii, Walid A.; Lee, Josephine W. (2000). "Balancing instrumental and identity goals in relationships: the role of respect directness and request persistence in the selection of sexual resistance strategies". Communication monographs, v. 67, n. 3, pp. 284-305.

https://doi.org/10.1080/03637750009376511

Allen, Louisa (2008). "They think you shouldn't be having sex anyway: young people's suggestions for improving sexuality education content". Sexualities, v. 11, n. 5, pp. 573-594.

https://doi.org/10.1177/1363460708089425

Amaya, Hector; Blair, Laura S. (2007). "Bridges between the divide: the female body in Y tu mama también and Muchacha". Studies in Hispanic cinemas, v. 4, n. 1, pp. 47-62.

https://doi.org/10.1386/shci.4.1.47/1

Anderson, Mike; Kunkel, Adrianne; Dennis, Michael R. (2011). "Let's not talk about that: bridging the past sexual experiences taboo to build healthy romantic relationships". Journal of sex research, v. 48, n. 4, pp. 381-391.

https://doi.org/10.1080/00224499.2010.482215

Angera, Jeffrey J.; Brookins-Fisher, Jodi; Inungu, Joseph N. (2008). "An investigation of parent/child communication about sexuality". American journal of sexuality education, v. 3, n. 2, pp. 165-181. https://doi.org/10.1080/15546120802104401

Aubrey, Jennifer S.; Yan, Kun; Terán, Larissa; Roberts, Lindsay (2020). "The heterosexual script on tween, teen and young-adult television programs: a content analysis update and extension". The journal of sex research, v. 57, n. 9, pp. 1134-1145.

https://doi.org/10.1080/00224499.2019.1699895 
Baumgartner, Susanne E.; Valkenburg, Patti M.; Peter, Jochen (2010a). "Assessing casualty in the relationship between adolescents' risky sexual online behavior and their perception of this behavior". Journal of youth and adolescence, v. 39, n. 10, pp. 1226-1239.

https://doi.org/10.1007/s10964-010-9512-y

Baumgartner, Susanne E.; Valkenburg, Patti M.; Peter, Jochen (2010b). “Unwanted online sexual solicitation and risky sexual online behavior across the lifespan". Journal of applied developmental psychology, v. 31, n. 6, pp. $439-447$.

https://doi.org/10.1016/j.appdev.2010.07.005

Baxter, Leslie A.; Bylund, Carma L.; Imes, Rebecca; Routsong, Tracy (2009). "Parent-child perceptions of parental behavioral control through rule-setting for risky health choices during adolescence". Journal of family communication, v. 9, n. 4, pp. $251-271$. https://doi.org/10.1080/15267430903255920

Bennett, Margaret; Denes, Amanda (2019). "Lying in bed: an analysis of deceptive affective messages during sexual activity in young adults' romantic relationships". Communication quarterly, v. 67, n. 2, pp. 140-157.

https://doi.org/10.1080/01463373.2018.1557722

Bisson, Melissa A.; Levine, Timothy R. (2009). "Negotiating a friends with benefits relationship". Archives of sexual behavior, v. 38, pp. 66-73.

https://doi.org/10.1007/s10508-007-9211-2

Bond, Bradley J. (2014). "Sex and sexuality in entertainment media popular with lesbian, gay and bisexual adolescents". Mass communication and society, v. 17, n. 1, pp. 98-120.

https://doi.org/10.1080/15205436.2013.816739

Bond, Bradley J. (2015). "Portrayals of sex and sexuality in gay-and-lesbian-oriented media: a quantitative content analysis". Sexuality \& culture, v. 19, n. 1, pp. 37-56.

https://doi.org/10.1007/s12119-01409241-6

Braithwaite, Dawn O.; Schrodt, Paul; Carr, Kristen (2015). "Meta-theory and theory in interpersonal communication research". In: Braithwaite, Dawn O.; Schrodt, Paul (eds.). Engaging theories in interpersonal communication: Multiple perspectives, $2^{\text {nd }}$ ed. Thousand Oaks: Sage, pp. 1-20. ISBN: 9781452261409

Brooks, Ann (2006). "Gendering knowledge". Theory, culture \& society, v. 23, n. 2-3, pp. 211-214. https://doi.org/10.1177/026327640602300246

Browning, James R.; Hatfield, Elaine; Kessler, Debra; Levine, Tim (2000). "Sexual motives, gender, and sexual behavior". Archives of sexual behavior, v. 29, n. 2, pp. 135-153.

https://doi.org/10.1023/A:1001903705153

Chapin, John (2001). 'It won't happen to me: the role of optimistic bias in African American teens' risky sexual practices". Howard journal of communication, v. 12, n. 1, pp. 49-59.

https://doi.org/10.1080/10646170119661

Chevrette, Roberta (2013). "Outing heteronormativity in interpersonal and family communication: feminist applications of queer theory "beyond the sexy streets'”. Communication theory, v. 23, n. 2, pp. 170-190.

https://doi.org/10.1111/comt.12009

Coffelt, Tina A. (2010). "Is sexual communication challenging between mothers and daughters?" Journal of family communication, v. 10, n. 2, pp. 116-130.

https://doi.org/10.1080/15267431003595496

Coffelt, Tina A. (2018). "Sexual goals, plans and actions: Toward a sexual script emerging adults use to delay or abstain from sexual intercourse". Western journal of communication, v. 82, n. 4, pp. 416-438.

https://doi.org/10.1080/10570314.2017.1400095

Coffelt, Tina A.; Hess, John A. (2014). "Sexual disclosures: Connections to relational satisfaction and closeness". Journal of sex \& marital therapy, v. 40, n. 6, pp. 577-591.

https://doi.org/10.1080/0092623X.2013.811449

Coffelt, A. Tina; Olsen, N. Loreen (2014). "No more birds and bees: A process approach to parent-child sexual communication". Annals of the International Communication Association, v. 38, n. 1, pp. 207-240.

https://doi.org/10.1080/23808985.2014.11679163

Comella, Lynn (2013). "Fifty shades of erotic stimulus". Feminist media studies, v. 13, n. 3, pp. 563-566.

https://doi.org/10.1080/14680777.2013.786269

Comella, Lynn; Sender, Katherine (2013). "Doing it: methodological challenges of communication research on sexuality". International journal of communication, v. 7, pp. 2560-2574.

https://ijoc.org/index.php/ijoc/article/view/2507 
Cowan, Renee L.; Horan, Sean M. (2014). "Why are you dating him? Contemporary motives for workplace romances". Qualitative research reports in communication, v. 15, n. 1, pp. 9-16.

https://doi.org/10.1080/17459435.2014.955587

Craft, Ashley-John (2012). "Love 2.0: a quantitative exploration of sex and relationships in the virtual world Second Life". Archives of sexual behavior, v. 41, n. 4, pp. 939-947.

https://doi.org/10.1007/s10508-012-9933-7

Craig, Robert T. (1999). "Communication theory as a field”. Communication theory, v. 9, pp. 119-161. https://doi.org/10.1111/j.1468-2885.1999.tb00355.x

Craig, Robert T.; Muller, Heidi L. (2007). Theorizing communication: Readings across traditions. Thousand Oaks: Sage. ISBN: 9781412952378

Cresswell, John W. (2014). Research design: Qualitative, quantitative, and mixed method approaches, $4^{\text {th }}$ ed. Thousand Oaks: Sage. ISBN: 9781452226101

Crowell, Tara L.; Emmers-Sommer, Tara M. (2001). "If I knew then what I know now: seropositive individuals' perceptions of partner trust, safety and risk prior to HIV infection". Communication studies, v. 52, n. 4, pp. 302-323. https://doi.org/10.1080/10510970109388566

Curnutt, Hugh (2012). "Flashing your phone: sexting and the remediation of teen sexuality". Communication quarterly, v. 60 , n. 3, pp. 353-369. https://doi.org/10.1080/01463373.2012.688728

Daneback, Kristian; Træen, Bente; Månsson, Sven-Axel (2009). “Use of pornography in a random sample of Norwegian heterosexual couples". Archives of sexual behavior, v. 38, n. 5, pp. 746-753.

https://doi.org/10.1007/s10508-008-9314-4

Denes, Amanda (2011). "Biology as consent: problematizing the scientific approach to seducing women's bodies". Women's studies international forum, v. 35, n. 5, pp. 411-419.

https://doi.org/10.1016/j.wsif.2011.05.002

Denes, Amanda (2012). "Pillow talk: exploring disclosures after sexual activity". Western journal of communication, v. 72, n. 2, pp. 91-108. https://doi.org/10.1080/10570314.2011.651253

Denes, Amanda (2013). "Engaging pillow talk: the challenges of studying communication after sexual activity". International journal of communication, v. 7, pp. 2495-2506.

https://ijoc.org/index.php/ijoc/article/viewFile/2252/1022

Denes, Amanda (2018). "Toward a post-sex disclosures model: exploring the associations among orgasm, self-disclosure, and relationship satisfaction". Communication research, v. 45, n. 3, pp. 297-318.

https://doi.org/10.1177/0093650215619216

Denes, Amanda; Afifi, Tamara D. (2014). Pillow talk and cognitive decision-making processes: exploring the influence of alcohol on communication after sexual activity". Communication monographs, v. 81, n. 3, pp. 333-358.

https://psycnet.apa.org/doi/10.1080/03637751.2014.926377

Denes, Amanda; Crowley, John P.; Makos, Shana; Whitt, Joseph; Graham, Kristen (2018). "Navigating difficult times with pillow talk: post sex communication as a strategy for mitigating uncertainty following relational transgressions". Communication reports, v. 31, n. 2, pp. 65-77.

https://doi.org/10.1080/08934215.2017.1386792

Denes, Amanda; Crowley, John P.; Winkler, Kara L.; Dhillon, Anuraj; Ponivas, Ambyre L. P.; Bennett, Margaret (2020). "Exploring the effects of pillow talk on relationship satisfaction and physiological stress responses to couples' difficult conversations". Communication monographs, v. 87, n. 3, art. 267290.

https://doi.org/10.1080/03637751.2020.1726424

Denes, Amanda; Dhillon, Anuraj; Speer, Annika C. (2017). "Relational maintenance strategies during the post sex time interval". Communication quarterly, v. 65, n. 3, pp. 307-332.

https://doi.org/10.1080/01463373.2016.1245206

Donovan, Sandra; Emmers-Sommer, Tara M. (2012). "Attachment style and gender as predictors of communicative responses to infidelity". Marriage \& family review, v. 48, n. 2, pp. 125-149.

https://psycnet.apa.org/doi/10.1080/01494929.2011.626670

Dougherty, Debbie S.; Kramer, Michael W.; Klatzke, Stephanie R.; Rogers, Teddy K. (2009). “Language convergence and meaning divergence: a meaning centered communication theory". Communication monographs, v. 76, n. 1, pp. $20-46$. https://doi.org/10.1080/03637750802378799 
Egan, R. Daniella; Hawkes, Gail (2009). "The problem with protection: or, why we need to move towards recognition and the sexual agency of children". Continuum: journal of media \& cultural studies, v. 23, n. 3, pp. 389-400. https://doi.org/10.1080/10304310902842975

Eguchi, Shinsuke; Calafell, Bernadette M.; Files-Thompson, Nicole (2014). Intersectionality and quare theory: fantasizing African American same-sex relationships in Noah's Arc: Jumping the broom". Communication, culture \& critique, v. 7, n. 3, pp. 371-389.

https://doi.org/10.1111/cccr.12054

Elia, John P. (2003). “Queering relationships: toward a paradigmatic shift”. Journal of homosexuality, v. 45, n. 2-4, pp. 61-86. https://doi.org/10.1300/J082v45n02_03

Emmers-Sommer, Tara M.; Farrell, Jenny; Gentry, Ashlyn; Stevens, Shannon; Eckstein, Justin; Battocletti, Joseph; Gardener, Carly (2010). "First date sexual expectations: the effects of who asked, who paid, date location and gender". Communication studies, v. 61, n. 3, pp. 339-355.

https://doi.org/10.1080/10510971003752676

Fernandez, Teena; Chapman, Jennifer; Estcourt, Claudia S. (2008). "Joint-working as a policy for reducing inequalities in access to information: developing culturally appropriate sex and relationships education for young Bangladeshis in London". Sex education, v. 8, n. 2, pp. 187-200.

https://doi.org/10.1080/14681810801981183

Foster, Elissa (2008). Commitment, communication, and contending with heteronormativity: an invitation to greater reflexivity in interpersonal research". Southern communication journal, v. 73, n. 1, pp. 84-101.

https://doi.org/10.1080/10417940701815683

Gavey, Nicola; McPhillips, Kathryn; Doherty, Marion (2001). "If it's not on, it's not on" - or is it? discursive constraints on women's condom use". Gender \& society, v. 15, n. 6, pp. 917-934.

https://doi.org/10.1177/089124301015006008

Gunning, Jacqueline N.; Cooke-Jackson, Angela; Rubinsky, Valerie (2020). "Negotiating shame, silence, abstinence, and period sex: women's shift from harmful memorable messages about reproductive and sexual health". American journal of sexuality education, v. 15, n. 1, pp. 111-137.

https://doi.org/10.1080/15546128.2019.1669511

Gupta, Kristina; Cacchioni, Thea (2013). "Sexual improvement as if your health depends on it: an analysis of contemporary sex manuals". Feminism \& psychology, v. 23, n. 4, pp. 442-458.

https://doi.org/10.1177/0959353513498070

Gupta, Antionette E.; Zimmerman, Toni S.; Fruhauf, Christine A. (2008). “Relationship advice in the top selling women's magazine Cosmopolitan: a content analysis". Journal of couple \& relationship therapy, v. 7, n. 3, pp. 248-266.

https://doi.org/10.1080/15332690802237987

Haig, Thomas (2006). "Bareback sex: masculinity, silence, and the dilemmas of gay health". Canadian journal of communication, v. 31, n. 4.

https://doi.org/10.22230/cjc.2006v31n4a1699

Hall, Jeffrey A. (2016). "Interpreting social-sexual communication: relational framing theory and social-sexual communication, attraction, and intent". Human communication research, v. 42, n. 1, pp. 138-164.

https://doi.org/10.1111/hcre.12071

Hall, Jeffrey A.; Xing, Chong; Brooks, Seth (2015). "Accurately detecting flirting: error management theory, the traditional sexual script, and flirting base rate". Communication research, v. 42, n. 7, pp. 939-958.

https://doi.org/10.1177/0093650214534972

Harvey, John H.; Wenzel, Amy; Sprecher, Susan (eds). (2004). The handbook of sexuality in close relationships. Mahwah, NJ: Lawrence Erlbaum. ISBN: 9780805845488

Henningsen, David-Dryden (2004). "Flirting with meaning: an examination of miscommunication in flirting interactions". Sex roles, v. 50, n. 7/8, pp. 481-489.

https://doi.org/10.1023/B:SERS.0000023068.49352.4b

Henningsen, David-Dryden; Braz, Mary; Davies, Elaine (2008). "Why do we flirt? Flirting motivations and sex differences in working and social contexts". Journal of business communication, v. 45, n. 4, pp. 483-502.

https://doi.org/10.1177/0021943608319390

Henningsen, David-Dryden; Henningsen, Mary-Lynn; Valde, Kathleen S. (2006). "Gender differences in perceptions of women's sexual interest during cross-sex interactions: an application and extension of cognitive valence theory". Sex roles, v. 54, n. 11-12, pp. 821-829.

https://doi.org/10.1007/s11199-006-9050-y 
Henningsen, David-Dryden; Kartch, Falon; Orr, Nancy; Brown, Amanda (2009). "The perceptions of verbal and nonverbal flirting cues in cross-sex interactions". Human communication, v. 12, n. 4, pp. 371-381.

https://www.scribd.com/document/162697333/The-Perceptions-of-Verbal-and-Nonverbal-Flirting-Cues-in-Cross-SexInteractions

Heisler, Jennifer M. (2005). "Family communication about sex: parents and college-aged offspring recall discussion topics, satisfaction, and parental involvement". The journal of family communication, v. 5, n. 4, pp. 295-312.

https://doi.org/10.1207/s15327698jfc0504_4

Hertzog, Jodie L. (2008). "What about the gray area?: College women's reflections on the sex talk and abstinence". Families in society, v. 89, n. 2, pp. 312-322.

https://doi.org/10.1606/1044-3894.3747

Hetsroni, Amir (2008). “Dependency and adolescents' perceived usefulness of information on sexuality: A cross-cultural comparison of interpersonal sources, professional sources, and the mass media". Communication reports, v. 21, n. 1, pp. 14-32.

https://doi.org/10.1080/08934210802019330

Hintz, Elizabeth A. (2018). "The vulvar vernacular: dilemmas experienced and strategies recommended by women with chronic genital pain". Health communication, v. 34, n. 14, pp. 1721-1720.

https://doi.org/10.1080/10410236.2018.1517709

Hintz, Elizabeth A. (2019). "Disrupting sexual norms: An application of the critical interpersonal and family communication (CIFC) framework in the context of vulvodynia". Journal of family communication, v. 19, n. 2, pp. 110-125.

https://doi.org/10.1080/15267431.2019.1580196

Holman, Amanda; Sillars, Alan (2012). "Talk about hooking up: the influence of college student social networks on nonrelationship sex". Health communication, v. 27, n. 2, pp. 205-216.

https://doi.org/10.1080/10410236.2011.575540

Horan, Sean M. (2016). "Further understanding sexual communication: honesty, deception, safety, and risk". Journal of social and personal relationships, v. 33, n. 4, pp. 449-468.

https://doi.org/10.1177/0265407515578821

Johnson, Amber (2014). "Confessions of a video vixen: my autocritography of sexuality, desire, and memory". Text and performance quarterly, v. 34, n. 2, pp. 182-200.

https://doi.org/10.1080/10462937.2013.879991

Jones, Daniel N.; Olderback, Sally G. (2014). "The associations among dark personalities and sexual tactics across different scenarios". Journal of interpersonal violence, v. 29, n. 6, pp. 1050-1070.

https://doi.org/10.1177/0886260513506053

Jozkowski, Kristen N. (2016). “Why does 'rape' seem like a myth?”. In: Manning, Jimmie; Noland, Carey M. (eds.). Contemporary studies of sexuality \& communication: theoretical and applied perspectives. Dubuque: Kendall Hunt, pp. 239261. ISBN: 9781465270245

Jozkowski, Kristen N.; Manning, Jimmie; Hunt, Mary (2018). "Sexual consent in and out of the bedroom: disjunctive views of heterosexual college students". Women's studies in communication, v. 41, n. 2, pp. 117-139. https://doi.org/10.1080/07491409.2018.1470121

Juárez, Fátima; Castro-Martín, Teresa (2006). "Safe sex versus safe love? Relationship context and condom use among male adolescents in the favelas of Recife, Brazil". Archives of sexual behavior, v. 35, n. 1, pp. 25-35.

https://doi.org/10.1007/s10508-006-8992-z

Kgafela, N. (2007). "Sexual actors or passive sexual gratifiers? Women lovers in Baralong Seboni's love poems". NAWA: Journal of language and communication, v. 1, n. 1, pp. 112-120.

Kirkman, Maggie; Rosenthal, Doreen A.; Feldman, S. Shirley (2005). "Being open with your mouth shut: the meaning of openness in family communication about sexuality". Sex education, v. 5, n. 1, pp. 49-66.

https://doi.org/10.1080/1468181042000301885

Knapp, Mark L.; Daly, John A. (2011). The SAGE handbook of interpersonal communication, $4^{\text {th }}$ ed. Thousand Oaks: Sage. ISBN: 9781412974745

Knobloch, Leanne K.; Delany, Amy L. (2012). "Themes of relational uncertainty and interference from partners in depression". Health communication, v. 27, n. 8, pp. 750-765.

https://psycnet.apa.org/doi/10.1080/10410236.2011.639293

Koelsch, Lori E. (2014). Sexual discourses and the absence of agency. Women \& language, v. 37, n. 2, pp. 11-29. 
Koelsch, Lori E.; Brown, Amy L.; Boisen, Leah (2012). “Bystander perceptions: implications for university sexual assault prevention programs". Violence and victims, v. 27, n. 4, pp. 563-579.

https://doi.org/10.1891/0886-6708.27.4.563

Kratzer, Jessica M. W.; Aubrey, Jennifer-Stevens (2016). "Is the actual ideal?: a content analysis of college students' descriptions of ideal and actual hookups". Sexuality \& culture, v. 20, n. 2, pp. 236-254.

https://doi.org/10.1007/s12119-015-9318-x

La-France, Betty H. (2010a). "Predicting sexual satisfaction in interpersonal relationships". Southern communication journal, v. 75, n. 3, pp. 195-214.

https://doi.org/10.1080/10417940902787939

La-France, Betty H. (2010b). "What verbal and nonverbal communication cues lead to sex? An analysis of the traditional sexual script". Communication quarterly, v. 58, n. 3, pp. 297-318.

https://doi.org/10.1080/01463373.2010.503161

La-France, Betty H. (2020). "Sexual interactions (un)scripted: an exploration of consequential unscripted sexual interactions". Communication quarterly, v. 68, n. 4, pp. 355-374.

https://doi.org/10.1080/01463373.2020.1787478

La-France, Betty H.; Henningsen, David D.; Oates, Aubrey; Shaw, Christina M. (2009). "Social-sexual interactions? Meta-analyses of sex differences in perceptions of flirtatiousness, seductiveness, and promiscuousness". Communication monographs, v. 76, n. 3, pp. 263-285.

https://doi.org/10.1080/03637750903074701

Lannutti, Pamela J.; Denes, Amanda (2012). A kiss is just a kiss? Comparing perceptions related to female-female and female-male kissing in a college social situation. Journal of bisexuality, v. 12, n. 1, pp. 49-62.

https://doi.org/10.1080/15299716.2012.645716

Levine, Stephen B. (2003). "The nature of sexual desire: a clinician's perspective”. Archives of sexual behavior, v. $32, \mathrm{n}$. 3, pp. 279-285.

https://doi.org/10.1023/A:1023421819465

Levine, Timothy R.; Aune, Krystyna-Styrzyewski; Park, Hee-Sun (2006). "Love styles and communication in relationships: partner preferences, initiation, and intensification". Communication quarterly, v. 54, n. 4, pp. 465-486.

https://doi.org/10.1080/01463370601036515

Levine, Timothy R.; Mongeau, Paul A. (2011). "Friends with benefits: A precarious negotiation”. In Bruce, Michael; Stewart, Robert M. (eds.). College sex-philosophy for everyone: philosophers with benefits. Oxford: Wiley/Blackwell, pp. 91-102. ISBN: 9781444332940

Lieser, Monica L.; Tambling, Rachel B.; Bischof, Gary H.; Murry, Nikita (2007). "Inclusion of sexuality in relationship education programs". The family journal, v. 15, n. 4, pp. 374-380.

https://doi.org/10.1177/1066480707304948

Liu, Min (2012). "Speaking the unspeakable: an exploratory study of college women's sex communication in Shanghai, China". Asian journal of communication, v. 22, n. 2, pp. 197-213.

https://doi.org/10.1080/01292986.2011.642396

Li, Yachao; Samp, Jennifer A. (2019). "Sexual relationship power, safer sexual communication, and condom use: A comparison of heterosexual young men and women". Western journal of communication, v. 83, n. 1, pp. 58-74.

https://doi.org/10.1080/10570314.2017.1398835

Lunceford, Brett (2008). "The walk of shame: a normative description". ETC: a review of general semantics, v. 64, n. 4, pp. 319-329.

https://www.jstor.org/stable/42578870

Lunceford, Brett (2009). "The body and the sacred in the digital age: thoughts on posthuman sexuality". Theology \& sexuality, v. 15, n. 1, pp. 77-96.

https://doi.org/10.1558/tse.v15i1.77

Lunceford, Brett (2011). “The new pornographers: Legal and ethical considerations of sexting. In Drushel, Bruce E.; German, Kathleen (eds.). The ethics of emerging media: Information, social norms, and new media technology. New York: Continuum International Publishing Group, pp. 99-118. ISBN: 9781441118363

Lunceford, Brett (2013a). "Telepresence and the ethics of digital cheating”. Explorations in media ecology, v. 12, n. 1-2, pp. 7-26.

https://doi.org/10.1386/eme.12.1-2.7_1 
Lunceford, Brett (2013b). "The real consequences of imaginary sex acts". ETC.: a review of general semantics, v. 70, n. 4, pp. 405-433.

https://www.researchgate.net/publication/261707609_The_Real_Consequences_of_Imaginary_Sex_Acts

MacLennan, Janet; Manning, Jimmie; Noland, Carey (2010). "Introduction”. In: Noland, Carey; Manning, Jimmie; MacLennan, Janet (eds.). Case studies of communication about sex. Newcastle: Cambridge Scholars, pp. xi-xxi. ISBN: 9781 443828758

Mahdavi, Pardis (2009). Passionate uprising: Iran's sexual revolution. Stanford: Stanford University: ISBN: 978080475 8567

Mandarelli, Gabrielle; Zangaro, Stefania; Raja, Michelle; Azzoni, Antonella; Tatarelli, Roberto; Ferracuti, Stefano (2012). "Competence to consent to sexual activity in bipolar disorder and schizophrenic spectrum disorders". Archives of sexual behavior, v. 41, n. 2, pp. 507-515.

https://doi.org/10.1007/s10508-011-9840-3

Manning, Jimmie (2011). "Masculinities in dating relationships: Reality and representation at the intersection of race, class, and sexual orientation". In: Watson, Elmwood; Shaw, Marc E. (eds.). Performing American masculinities: The 21 ${ }^{\text {st }}$ century man in popular culture. Bloomington: Indiana University, pp. 167-191. ISBN: 9780253222701

Manning, Jimmie (2013). "Interpretive theorizing in the seductive world of sexuality and interpersonal communication: getting guerilla with studies of sexting and purity rings". International journal of communication, v. 7, pp. 2507-2520. https://ijoc.org/index.php/ijoc/article/download/2250/1023

Manning, Jimmie (2014a). "Coming out conversations and gay/bisexual men's sexual health: a constitutive model study”. In: Harvey, Vickie L.; Housel, Teresa-Heinz (eds.). Health care disparities and the LGBT population. Lanham: Lexington Books, pp. 27-54. ISBN: 9781498536059

Manning, Jimmie (2014b). "Communication and healthy sexual practices: Toward a holistic communicology of sexuality". In: Eaves, Michael H. (ed.). Applications in health communication: emerging trends. Dubuque: Kendall Hunt, pp. 263-286. ISBN: 9781465237873

Manning, Jimmie (2014c). "A constitutive approach to interpersonal communication studies". Communication studies, v. 65, n. 4 , pp. $432-440$.

https://doi.org/10.1080/10510974.2014.927294

Manning, Jimmie (2014d). "Exploring family discourses about purity pledges: connecting relationships and popular culture". Qualitative research reports in communication, v. 15, n. 1, pp. 92-99.

https://doi.org/10.1080/17459435.2014.955597

Manning, Jimmie (2015a). "Communicating sexual identities: A typology of coming out”. Sexuality \& culture, n. 1, pp. 122-138.

https://doi.org/10.1007/s12119-014-9251-4

Manning, Jimmie (2015b). "Ipsedixitism, ipseity, and ipsilateral identity: The fear of finding ourselves in the fissures between phishing and catfish". In: Herbig, Arthur; Hermann, Andrew; Tyma, Adam (eds.). Beyond new media: discourse and critique in a polymediated age. Lanham: Lexington Books, pp. 83-107. ISBN: 9781498507370

Manning, Jimmie (2015c). "Paradoxes of (im)purity: affirming heteronormativity and queering heterosexuality in family discourses of purity pledges". Women's studies in communication, v. 38, n. 1, pp. 99-117.

https://doi.org/10.1080/07491409.2014.954687

Manning, Jimmie (2015d). "Positive and negative communicative behaviors in coming-out conversations". Journal of homosexuality, v. 62, n. 1, pp. 67-97.

https://doi.org/10.1080/00918369.2014.957127

Manning, Jimmie (2017). "Examining health and relationship beliefs in family discourses about purity pledges: gender, faith values, and the communicative constitution of reality". Western journal of communication, v. 81, n. 1, pp. 87-104. https://doi.org/10.1080/10570314.2016.1227082

Manning, Jimmie (2020). “Queering family communication”. In: Soliz, Jordan; Warner-Colaner, Colleen (eds.). Navigating relationships in the modern family: communication, identity, and difference. New York: Peter Lang, pp. 69-95. ISBN: 9781433162374

Manning, Jimmie; Adams, Tony E. (in press). “Queer theory: Troubling interpersonal expectations of sex, gender, and sexuality". In: Braithwaite, Dawn; Schrodt, Paul (eds.). Engaging theories in interpersonal communication: Multiple perspectives ( $3^{\text {rd }}$ ed.). New York: Routledge. 
Manning, Jimmie; Adams, Tony E.; Atay, Ahmet (2020). “Gay, Grey, gray, and play: fifty shades queer. In: Kratzer, Jessica M. W. (ed.). Communication in kink: understanding the influence of the Fifty Shades of Grey phenomenon. Lanham: Lexington Books, pp. 217-228. ISBN: 9781498585507

Manning, Jimmie; Asante, Godfried; Huerta-Moreno, Lydia; Johnson, Rebecca; LeMaster, Benny; Li, Yachao; Rudnick, Justin J.; Stern, Danielle M.; Young, Stephanie (2020). “Queering communication studies: a Journal of Applied Communication Research forum". Journal of applied communication research, v. 48, n. 4, pp. 413-437. https://doi.org/10.1080/00909882.2020.1789197

Manning, Jimmie; Stern, Danielle M. (2016). “Heteronormative bodies, queer futures: Toward a theory of interpersonal panopticism". Information, communication \& society, v. 21, n. 2, pp. 208-223.

https://doi.org/10.1080/1369118X.2016.1271901

Manning, Jimmie; Kunkel, Adrianne (2014a). “Making meaning of meaning-making research: using qualitative research methods for studies of social and personal relationships". Journal of social and personal relationships, v. 31, n. 4, pp. 433-441.

https://doi.org/10.1177/0265407514525890

Manning, Jimmie; Kunkel, Adrianne (2014b). Researching interpersonal relationships: qualitative methods, studies and analysis. Thousand Oaks: Sage. ISBN: 9781452203904

Miller, Michael J.; Denes, Amanda; Diaz, Brianna; Buck, Ross (2014). "Attachment style predicts jealous reactions to viewing touch between a romantic partner and close friend: Implications for internet social communication". Journal of nonverbal behavior, v. 38, n. 4, pp. 451-476.

https://doi.org/10.1007/s10919-014-0196-y

Mongeau, Paul A.; Jacobsen, Janet; Donnerstein, Carolyn (2007). “Defining dates and first date goals: generalizing from undergraduates to single adults". Communication research, v. 34, n. 5, pp. 526-547.

https://doi.org/10.1177/0093650207305235

Mongeau, Paul A.; Knight, Kendra; Williams, Jade; Eden, Jennifer; Shaw, Christina (2013). "Identifying and explicating variation among friends with benefits relationships". Journal of sex research, v. 50, n. 1, pp. 37-47.

https://doi.org/10.1080/00224499.2011.623797

Mongeau, Paul A.; Morr-Serewicz, Mary-Claire; Ficara-Therrien, Lona (2004). “Goals for cross-sex first dates: identification, measurement, and the influence of contextual factors". Communication monographs, v. 71, n. 2, pp. 121-147. https://doi.org/10.1080/0363775042331302514

Morr-Serewicz, Mary-Claire; Mongeau, Paul A. (2004). "First-date expectations, the impact of sex of initiator, alcohol consumption, and relationship type. Communication research, v. 31, n. 1, pp. 3-35.

https://doi.org/10.1177/0093650203260202

Noland, Carey M. (2006). "Listening to the sound of silence: Gender roles and communication about sex in Puerto Rico". Sex roles, v. 55, n. 5-6, pp. 283-294.

https://doi.org/10/1007/s11199-006-9083-2

Noland, Carey M. (2008). "Macho men don't communicate: the role of communication in HIV prevention". The journal of men's studies, v. 16, n. 1, pp. 18-31.

https://doi.org/10.3149/jms.1601.18

Noland, Carey M. (2010). Sex talk: The role of communication in intimate relationships. Santa Barbara: Praeger. ISBN: 9780313379680

Noland, Carey M.; MacLennan, J . (2006). “Perplexing questions about culture, gender, and sex research: why isn't awareness enough?". Texas speech communication journal, v. 30, n. 2, pp. 158-169.

Nyanzi, Stella; Nyanzi-Wokholi, Barbara; Kalina, Bessie (2009). "Male promiscuity: the negotiation of masculinities by motorbike taxi-riders in Masaka, Uganda". Men and masculinities, v. 12, n. 1, pp. 73-89.

https://doi.org/10.1177/1097184X07309503

O’Higgins, Siobhán; Gabhainn, Saoirse-Nic (2010). "Youth participation in setting the agenda: learning outcomes for sex education in Ireland". Sex education, v. 10, n. 4, pp. 387-403.

https://doi.org/10.1080/14681811.2010.515096

Parker, Kimberly A.; Ivanov, Bobi (2013). "Why not communicate? Young women's reflection on their lack of communication with sexual partners regarding sex and contraception". International journal of health, wellness, and society, v. 2 , n. 4, pp. 93-109.

https://doi.org/10.18848/2156-8960/CGP/v02i04/41023 
Payne, Robert (2014). "Frictionless sharing and digital promiscuity". Communication and critical/cultural studies, v. 11, n. 2, pp. 85-102. https://doi.org/10.1080/14791420.2013.873942

Peck, Brittnie; Manning, Jimmie; Tri, Andrew; Skrzypczynski, Daria; Summers, Morgan; Grubb, Kayleigh (2016). "What do people mean when they say they had sex? Connecting communication and behavior. In: Manning, Jimmie; Noland, Carey M. (eds.). Contemporary studies of sexuality \& communication: theoretical and applied perspectives. Dubuque: Kendall Hunt, pp. 3-14. ISBN: 9781465270245

Peter, Jochen; Valkenburg, Patti M. (2007). "Who looks for casual dates on the internet? A test of the compensation and the recreation hypotheses". New media \& society, v. 9, n. 3, pp. 455-474.

https://doi.org/10.1177/1461444807076975

Raffaelli, Marcela; Green, Stephanie (2003). "Parent-adolescent communication about sex: retrospective reports by Latino college students". Journal of marriage and family, v. 65, n. 2, pp. 474-481.

https://doi.org/10.1111/j.1741-3737.2003.00474.x

Ren, Pega (2007). "Coping with premature ejaculation: how to overcome PE, please your partner \& have great sex". Archives of sexual behavior, v. 36, pp. 475-476.

https://doi.org/10.1007/s10508-007-9173-4

Rhucharoenpornpanich, Orratai; Chamratrithirong, Aphichat; Fongkaew, Warunee; Miller, Brenda A.; Cupp, Pamela K.; Rosati, Michael J.; Byrnes, Hilary F.; Atwood, Katharine A.; Chookhare, Warunee (2012). "Parent-teen communication about sex in urban Thai families". Journal of health communication, v. 17, n. 4, pp. 380-396.

https://doi.org/10.1080/10810730.2011.626668

Rinaldi-Miles, Anna; Quick, Brian; LaVoie, Nicole (2014). “An examination of the principles of influence on condom use decision making during casual sex encounters". Health communication, v. 29, n. 6, pp. 531-541.

https://doi.org/10.1080/10410236.2013.765295

Ross, Michael W.; Rosser, B. R. Simon; McCurdy, Sheryl; Feldman, Jamie (2007). "The advantages and limitations of seeking sex online: a comparison of reasons given for online and offline sexual liasons by men who have sex with men". Journal of sex research, v. 44, n. 1, pp. 59-71.

https://doi.org/10.1080/00224490709336793

Rubinsky, Valerie (2018). "Sometimes it's easier to type things than to say them: technology in BDSM sexual partner communication". Sexuality \& culture, v. 22, n. 4, pp. 1412-1431.

https://doi.org/10/1007/s12119-018-9534-2

Rubinsky, Valerie (2021). "Sources and strategies for managing sexual conflict in diverse relationships". Sexuality \& culture. https://doi.org/10.1007/s12119-020-09800-x

Simpson, Paul (2012). "Perils, precariousness and pleasures: middle-aged gay men negotiating urban heterospaces". Sociological research online, v. 17, n. 3, pp. 124-133.

https://doi.org/10.5153/sro.2665

Smahel, David; Wright, Michelle; Cernikova, Martina (2014). "Classification of online problematic situations in the context of youths' development". Communications, v. 39, n. 3, pp. 233-260.

https://doi.org/10.1515/commun-2014-0111

Sprecher, Susan; Cate, Rodney M. (2004). "Sexual satisfaction and sexual expression as predictors of relationship satisfaction and stability". In: Harvey, John H; Wenzel, Amy; Sprecher, Susan (eds.). The handbook of sexuality in close relationships. Mahwah: Lawrence Erlbaum, pp. 235-256. ISBN: 9780805856682

Sprecher, Susan; Christopher, F. Scott; Cate, Rodney M. (2006). "Sexuality in close relationships". In: Vangelisti, Anita L.; Perlman, Daniel (eds.). The Cambridge handbook of personal relationships. New York: Cambridge University, pp. 463482. ISBN: 9781107571204

Sprecher, Susan; Harris, Gardenia; Meyers, Adena (2008). "Perceptions of sources of sex education and targets of sex communication: sociodemographic and cohort effects". Journal of sex research, v. 45, n. 1, pp. 17-26.

https://doi.org/10.1080/00224490701629522

Stamp, Glen H. (1999). "A qualitatively constructed interpersonal communication model: A grounded theory analysis". Human communication research, v. 25, n. 4, pp. 531-547.

https://doi.org/10.1111/j.1468-2958.1999.tb00460.x

Štulhofer, Alexsandar; Buško, Vesna; Brouillard, Pamela (2010). "Development and bicultural validation of the new sexual satisfaction scale". Journal of sex research, v. 47, n. 4, pp. 257-268.

https://doi.org/10.1080/00224490903100561 
Theiss, Jennifer; Estlein, Roi (2014). "Antecedents and consequences of the perceived threat of sexual communication: a test of the relational turbulence model". Western journal of communication, v. 78, n. 4, pp. 404-425.

https://doi.org/10.1080/10570314.2013.845794

Van-der-Stege, Heleen A.; Van-Staa, AnneLoes; Hilberink, Sander R.; Visser, Adriaan Ph. (2010). "Using the new board game SeCZ TaLK to stimulate the communication on sexual health for adolescents with chronic conditions". Patient education and counseling, v. 81, n. 3, pp. 324-331.

https://doi.org/10.1016/j.pec.2010.09.011

Widman, Laura; Golin, Carol E.; Kamke, Kristyn; Burnette, Jeni L.; Prinstein, Mitchell J. (2018). "Sexual assertiveness skills and sexual decision-making in adolescent girls: randomized controlled trial of an online program". American journal of public health, v. 108, n. 1, pp. 96-102.

https://ajph.aphapublications.org/doi/10.2105/AJPH.2017.304106

Woodward, Anne J.; Findlay, Bruce M.; Moore, Susan M. (2009). "Peak and mystical experiences in intimate relationships". Journal of social and personal relationships, v. 26, n. 4, pp. 429-442.

https://doi.org/10.1177/0265407509339994

Wright, Paul J. (2009). "Father-child sexual communication in the United States: a review and synthesis". Journal of family communication, v. 9, n. 4, pp. 233-250.

https://doi.org/10.1080/15267430903221880

Wright, Paul J.; Randall, Ashley K.; Hayes, Javette-Grace (2012). "Predicting the condom assertiveness of collegiate females in the United States from the expanded health belief model". International journal of sexual health, v. 24, n. 2, pp. 127-153.

https://doi.org/10.1080/19317611.2012.661396

Wyckoff, Sarah C.; Miller, Kim S.; Forehand, Rex; Bau, J. J.; Fasula, Amy; Long, Nicholas; Armistead, Lisa (2008). "Patterns of sexuality communication between preadolescents and their mothers and fathers". Journal of child and family studies, v. 17, n. 5, pp. 649-662.

https://doi/org/10.1007/s10826-007-9179-5

Yeo, Tien-Ee-Dominic; Fung, Tsz-Hin (2016). "Between 0 and 1: safer sex and condom use among young gay men in Hong Kong". Culture, health \& sexuality, v. 18, n. 3, pp. 294-307.

https://doi.org/10.1080/13691058.2015.1080298

Yeo, Tien-Ee-Dominic; Chu, Tsz-Hang (2017). "Sharing sex secrets on Facebook: a content analysis of youth peer communication and advice exchange on social media about sexual health and intimate relations". Journal of health communication, v. 22, n. 9, pp. 753-762.

https://doi.org/10.1080/10810730.2017.1347217

Yep, Gust A. (2003). "The violence of heteronormativity in communication studies: notes on injury, healing and queer world-making". Journal of homosexuality, v. 45, n. 2-4, pp. 11-59.

https://doi.org/10.1300/J082v45n02_02

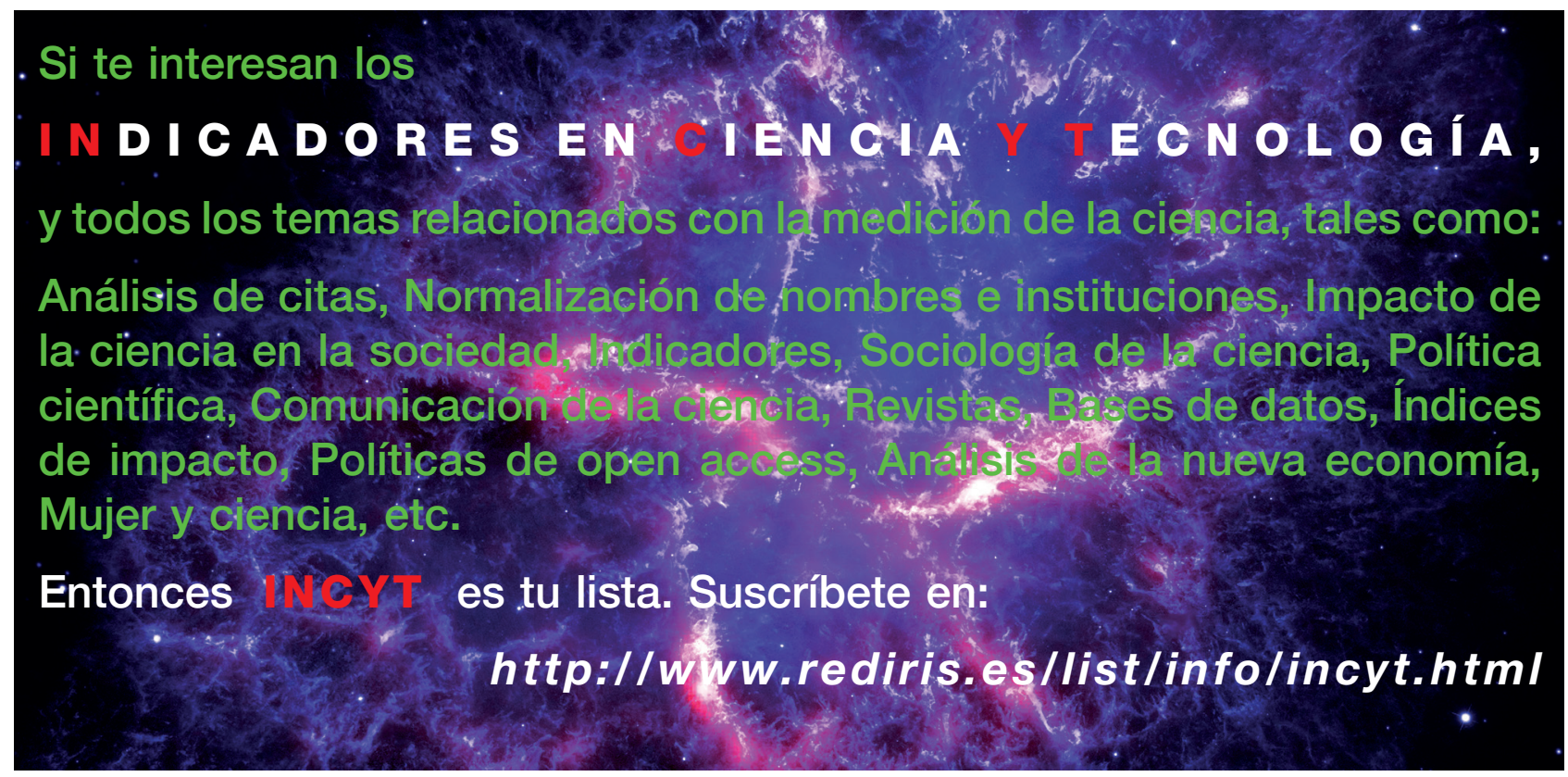

